\title{
The Lonidamine Derivative H2-Gamendazole Reduces Cyst Formation in Polycystic Kidney Disease
}

\author{
Shirin V. Sundar ${ }^{1,2}$, Xia Zhou ${ }^{2,3}$, Brenda S. Magenheimer ${ }^{1,2}$, Gail A. Reif ${ }^{2,3}$, \\ Darren P. Wallace ${ }^{2,3}$, Gunda I. Georg ${ }^{4}$, Sudhakar R. Jakkaraj ${ }^{4}$, Joseph S. Tash ${ }^{5}$, \\ Alan S.L. $\mathrm{Yu}^{2,3}$, Xiaogang $\mathrm{Li}^{2,3,6}$, and James P. Calvet ${ }^{1,2^{*}}$ \\ ${ }^{1}$ Department of Biochemistry and Molecular Biology, University of Kansas Medical Center, \\ Kansas City, KS \\ ${ }^{2}$ Jared Grantham Kidney Institute, University of Kansas Medical Center, Kansas City, KS \\ ${ }^{3}$ Department of Internal Medicine, Division of Nephrology and Hypertension, University of \\ Kansas Medical Center, Kansas City, KS \\ ${ }^{4}$ Department of Medicinal Chemistry and Institute for Therapeutics Discovery and Development, \\ University of Minnesota, Minneapolis, MN \\ ${ }^{5}$ Department of Molecular and Integrated Physiology, University of Kansas Medical Center, \\ Kansas City, KS \\ ${ }^{6}$ Department of Internal Medicine and Department of Biochemistry and Molecular Biology, Mayo \\ Clinic, Rochester, MN \\ *Correspondence: \\ James P. Calvet, PhD \\ Department of Biochemistry and Molecular Biology \\ The Jared Grantham Kidney Institute \\ University of Kansas Medical Center \\ 3901 Rainbow Blvd. \\ Kansas City, KS 66160 \\ 913-588-9252 \\ jcalvet@kumc.edu \\ Current Addresses: \\ Dr. Shirin V. Sundar, Otsuka Pharmaceutical Development \& Commercialization, Inc., \\ Princeton, NJ \\ Dr. Xia (Julie) Zhou, Advent Health, Orlando, FL \\ Dr. Xiaogang Li, Mayo Clinic, Rochester, MN
}

Keywords: ADPKD, Hsp90, CFTR, actin cytoskeleton, cell motility, metanephric organ culture, cell proliferation, fluid secretion 


\begin{abstract}
Autosomal dominant polycystic kidney disease (ADPKD) is a debilitating renal neoplastic disorder with limited treatment options. It is characterized by the formation of large fluid-filled cysts that develop from kidney tubules through abnormal cell proliferation and cystfilling fluid secretion driven by cAMP-dependent $\mathrm{Cl}^{-}$secretion. We have examined the effectiveness of the indazole carboxylic acid, H2-gamendazole (H2-GMZ), a derivative of lonidamine, to inhibit these processes and cyst formation using in vitro and in vivo models of ADPKD. H2-GMZ was effective in rapidly blocking forskolin-induced, $\mathrm{Cl}^{-}$-mediated short-circuit currents in human ADPKD cells at $1 \mu \mathrm{M}$ and it significantly inhibited both cAMP- and EGFinduced proliferation of ADPKD cells with an IC50 of 5-10 $\mu \mathrm{M}$. Western blot analysis of $\mathrm{H} 2$ GMZ-treated ADPKD cells showed decreased phosphorylated ERK and hyperphosphorylated $\mathrm{Rb}$ levels. H2-GMZ treatment also decreased ErbB2, Akt, and Cdk4, consistent with inhibition of the chaperone Hsp90, and reduced the levels of the CFTR $\mathrm{Cl}^{-}$channel. H2-GMZ-treated ADPKD cultures contained a higher proportion of smaller cells with fewer and smaller lamellipodia and decreased cytoplasmic actin staining, and they were unable to accomplish wound closure even at low H2-GMZ concentrations, consistent with an alteration in the actin cytoskeleton and decreased cell motility. Studies using mouse metanephric organ cultures showed that $\mathrm{H} 2-\mathrm{GMZ}$ inhibited cAMP-stimulated cyst growth and enlargement. In vivo, $\mathrm{H} 2-$ GMZ $(20 \mathrm{mg} / \mathrm{kg})$ was effective in slowing postnatal cyst formation and kidney enlargement in the Pkd1 flox/flox:Pkhd1-Cre mouse model. Thus, $\mathrm{H} 2-\mathrm{GMZ}$ treatment decreases $\mathrm{Cl}^{-}$secretion, cell proliferation, cell motility, and cyst growth. These properties, along with its reported low toxicity, suggest that H2-GMZ might be an attractive candidate for treatment of ADPKD.
\end{abstract}




\section{INTRODUCTION}

Autosomal dominant polycystic kidney disease (ADPKD) affects an estimated 1 in 4001,000 people worldwide (1-4). ADPKD is characterized by the progressive growth of large fluidfilled cysts in a number of ductal organs, but predominantly in the kidneys. The steady growth and enlargement of kidney cysts ultimately leads to end stage renal disease (ESRD) in about $50 \%$ of patients by age $50-60$ years and accounts for $6-9 \%$ of patients on renal replacement therapy $(2,5,6)$. Many years of productive life are lost due to the debilitating complications of PKD, which include hypertension, hematuria, abdominal pain, and kidney infection $(7,8)$. Blood pressure control has been partially effective in the clinical management of the disease $(8,9)$.

In ADPKD, renal cyst growth requires two mechanisms-proliferation of cyst-lining epithelial cells and secretion of fluid into the cyst lumen (10-12). The cellular second messenger cyclic adenosine monophosphate (cAMP) plays a vital role in promoting both fluid secretion and cell proliferation in ADPKD (13-17). Cyclic AMP acts downstream of G-protein coupled receptors, such as the arginine vasopression (AVP) V2 receptor, to activate PKA. This leads to phosphorylation and activation of CFTR to promote $\mathrm{Cl}^{-}$secretion followed by fluid secretion into the cyst lumen $(16,18)$. Activation of PKA by cAMP also elicits a strong mitogenactivated protein (MAP) kinase response in ADPKD cells, which are primed to be activated by decreased cytosolic calcium caused by PKD mutation $(17,19,20)$. As an understanding of the molecular mechanisms of ADPKD progression has grown in recent years, so has the number of potential therapies (1-3,21-34), including drugs that target cAMP-dependent fluid secretion and target cell growth and proliferation. One such drug is the AVP V2 receptor antagonist, tolvaptan, which has been approved by the U.S. Food and Drug Administration (FDA) for the treatment of adult patients with ADPKD (17,35-39); however, high cost and side effects, including polyuria, nocturia, thirst, and liver complications limit its use in some patients. Many other drugs that have entered clinical trials for ADPKD have been repurposed from non-PKD indications $(3,40,41)$. While many of these drugs show promise, concerns have been raised regarding their long-term use and safety profiles (42-45). To be an effective therapy for ADPKD, drugs will need to be efficacious and well tolerated over decades, since cyst growth is slow. As such, there is a need to develop drugs for PKD that have excellent safety profiles and can target both fluid secretion and cell proliferation to successfully reduce cyst growth over a lifetime while preserving normal renal function.

Indazole-carboxylic acids are a class of drugs with the potential to target the cellular machinery implicated in the pathogenesis of PKD. Lonidamine (LND) is best known for its antispermatogenic and anti-cancer properties $(46,47)$. LND has been shown to inhibit cAMPinduced CFTR-mediated anion secretion $(48,49)$ as an open channel inhibitor of CFTR $(50)$, making it and this class of drugs potential candidates for inhibiting cyst-filling fluid secretion in PKD. LND also affects a number of other cellular processes, including lactate transport and the mitochondrial metabolic pathway for aerobic glycolysis and oxygen consumption (51), inducing apoptosis. More recently, one of the derivatives of LND, gamendazole (GMZ), which was developed at the University of Kansas, was shown to inhibit the Hsp90 pathway, although the mechanism is still a matter of investigation (52-54), and to decrease the levels of the proteins Her2 (ErbB2) and Akt in MCF-7 cells (52). In addition, GMZ was found to associate with the eukaryotic elongation factor eEF1A1. GMZ and another derivative H2-GMZ have been under investigation as male contraceptives. As such, they have excellent safety profiles and bioavailability, and their effects on the testis are reported to be reversible (55).

$\mathrm{H} 2-\mathrm{GMZ}$ has been shown (using proteolytic fingerprinting and affinity chromatography) to modulate Hsp90 function by a mechanism similar to the natural product celastrol (53). The molecular chaperone Hsp90 has proven to be an important drug target for the treatment of 
various neoplastic disorders. Hsp90 is a ubiquitous protein, abundant in the cell and required for normal function (56,57). Hsp90 promotes the maturation and proper folding of more than a hundred substrate or "client" proteins in the cell. Hsp90 inhibitors are of growing therapeutic interest because client proteins are frequently mutated, over-expressed, or functionally active in cancer, thus making these cells more dependent on a finite supply of Hsp90. Various classes of Hsp90 inhibitors currently being tested as anti-cancer agents have been reviewed extensively (58-63). These agents bind distinct Hsp90 domains or co-chaperones such as cdc37, inhibit their function and cause proteasomal degradation of their client proteins, including numerous protein kinases, transcription factors and cell surface receptors, leading to decreased cell proliferation. Many Hsp90 client proteins have been implicated in the pathogenesis of PKD, including but not limited to ErbB2 $(64,65)$, CFTR $(66,67)$, Akt $(68,69)$, cyclin dependent kinases (70), and proteins of the MEK-ERK pathway (71-74). The Hsp90 inhibitors STA-2842 and STA-9090 (ganetespib) have been shown to reduce cyst size and disease progression in mouse models PKD (75-77). However, the role of the Hsp90 chaperone complex in human ADPKD cells has not been investigated.

Ultimately, we are interested in developing H2-GMZ and its derivatives as a therapeutic for ADPKD based on the ability of the parent compound, LND, to block CFTR channel activity and inhibit cell proliferation. As such, we tested whether H2-GMZ can target both fluid secretion and cell proliferation in human ADPKD cells. To this end, we investigated the effect of $\mathrm{H} 2-\mathrm{GMZ}$ on CFTR-mediated $\mathrm{Cl}^{-}$secretion in ADPKD cells and whether $\mathrm{H} 2-\mathrm{GMZ}$ can inhibit $\mathrm{Hsp} 90$ client proteins and cell motility. We further investigated the potential of $\mathrm{H} 2-\mathrm{GMZ}$ to target cyst formation and enlargement in a mouse metanephric organ culture model and in vivo in a Pkd1 conditional mouse. Our results suggest that $\mathrm{H} 2-\mathrm{GMZ}$ could be effective against ADPKD cyst growth.

\section{METHODS}

H2-GMZ: H2-gamendazole (3-[1-(2,4-dichlorobenzyl)-6-trifluoromethyl-1H-indazol-3-yl]propionic acid) (JWS-2-72) was initially described in (52) and U.S. Patent US8362031B2.

Cell culture: Primary cultures of human ADPKD cyst-lining epithelial cells and normal human kidney (NHK) cells were obtained from the PKD Biomarkers, Biomaterials, and Cellular Models Core in the Kansas PKD Center. The use of discarded clinical specimens is considered to be not human subjects research by regulatory agencies and the institutional board at the University of Kansas Medical Center. The generation and use of primary ADPKD and NHK cells have been described in detail $(78,79)$. Cells were maintained in a $37^{\circ} \mathrm{C}$ humidified $\mathrm{CO}_{2}$ incubator in DMEM/F12 medium containing 1\% FBS and supplemented with insulin, transferrin and selenium (ITS). The mouse cortical collecting duct cell line M-1 (80) was maintained in DMEM/F12 medium containing 5\% FBS.

Chloride ion secretion assay: Anion secretion was determined by measuring short-circuit current across human ADPKD cells. Briefly, confluent monolayers of ADPKD cells on Snapwell supports were inserted into modified Ussing chambers (Harvard Apparatus), and both surfaces were bathed in a $\mathrm{HCO}_{3}$-Ringer's solution maintained at $37^{\circ} \mathrm{C}$ and equilibrated in $5 \% \mathrm{CO}_{2}-95 \%$ $\mathrm{O}_{2}$. Electrodes were positioned within the chambers and short-circuit current (Isc) was measured using two dual-voltage-clamp devices (Warner Instruments). Positive Isc reflects the sum of active transport of cations (e.g., $\mathrm{Na}^{+}$) from the apical to basolateral surface and anions (e.g., $\mathrm{Cl}^{-}$) from the basolateral to apical surface. Benzamil was added to inhibit cation transport 
via the epithelial $\mathrm{Na}^{+}$channel ENaC. Forskolin, a potent cAMP agonist, was added to stimulate the $\mathrm{Cl}^{-}$current. Isc was continuously monitored and recorded with LabChart7 (AD Instruments).

Cell proliferation assay: ADPKD cell proliferation was measured using the Promega Cell Titer 96 MTT assay kit as described previously $(12,13)$. Cells were plated at a density of $4 \mathrm{x}$ $10^{3}$ per well in a 96-well cell culture plate in medium containing $1 \%$ FBS + ITS. Cells were serum-starved for $24 \mathrm{~h}$ and treated either with $100 \mu \mathrm{M}$ cAMP or $25 \mathrm{ng} / \mathrm{ml}$ EGF to stimulate cell proliferation or were placed directly in 5\% FBS-containing medium. Increasing concentrations of H2-GMZ or LND were added to the medium to determine their effect on cell proliferation. After $72 \mathrm{~h}$ of treatment, MTT assays were performed by adding dye solution to the cells and stopping the reaction $4 \mathrm{~h}$ later. Optical densities measured using a spectrophotometer were considered to be directly proportional to the number of viable cells present.

Mitotic index: ADPKD cells $\left(5 \times 10^{3}\right.$ per well) were plated in 4-well chamber slides in medium containing 1\% FBS + ITS. After 24 hours, medium was changed to include $5 \%$ FBS. Cells were treated with increasing concentrations of $\mathrm{H} 2-\mathrm{GMZ}$ for $16 \mathrm{~h}$, fixed with $4 \%$ paraformaldehyde and permeabilized with $0.2 \%$ Triton-X 100 . Cells were mounted using ProLong Gold antifade reagent containing DAPI (Thermo Fisher Scientific) and observed by fluorescence microscopy. Eight to 10 separate fields were examined at 10x magnification and the number of mitotic nuclei were counted and expressed as a percentage of the total number of nuclei per field.

Western blotting: ADPKD cells were seeded on 6-well culture plates and treated with $50 \mu \mathrm{M}$ H2-GMZ for various time points. Cytoplasmic protein extracts were prepared by lysing cells in ice-cold lysis buffer (10 mM Tris-Cl pH 7.5, 150 mM NaCl, 2 mM EDTA pH 8.0, 1\% Triton X100, 0.5\% NP-40, 25 mM glycerol 2-phosphate, $1 \mathrm{mM}$ sodium orthovanadate, $1 \mathrm{mM}$ phenylmethyl sulfonyl fluoride, and $0.1 \% \mathrm{v} / \mathrm{v}$ Sigma protease inhibitor cocktail). Nuclei and other Triton-insoluble components were removed by high speed centrifugation. Protein concentration was measured using the Pierce BCA assay kit. $20 \mu \mathrm{g}$ total protein was boiled with SDS sample buffer and fractionated on 7.5, 10 or $12.5 \%$ SDS-PAGE gels. Proteins were transferred to PVDF membranes and non-specific binding blocked with $5 \%$ powdered milk in TBS-T (10 mM Tris-Cl pH 7.5, $150 \mathrm{mM} \mathrm{NaCl}$, and 0.1\% Tween 20) for $1 \mathrm{~h}$ at room temperature. Blocked membranes were incubated with primary antibodies in $5 \%$ powdered milk or $5 \%$ BSA (for phospho-proteins) in TBS-T overnight at $4^{\circ} \mathrm{C}$. Membranes were then washed three times with TBS-T and incubated with alkaline phosphatase-conjugated secondary antibodies (Sigma) in 5\% milk in TBS-T for $30 \mathrm{~min}$ at room temperature. The membranes were washed three times with TBS-T and protein bands were visualized using the CDP-star detection reagent (GE Healthcare). Intensity was detected and quantitatively analyzed by the Fluor-S MAX multi-imager system (Bio-Rad). Antibodies used for Western blotting were p-ERK, Actin (Sigma), ERK1, ERK2, ErbB2, Rb, Cdk4 (Santa Cruz), Hsp90, Hsp70, Akt, GAPDH (Cell Signaling), and CFTR (R\&D Systems).

Immunoprecipitation: ADPKD cells were plated at a density of $1 \times 10^{6}$ cells per flask in medium containing 5\% FBS. Cells were lysed after $24 \mathrm{~h}$ in gentle lysis buffer (10 mM Tris-Cl $\mathrm{pH}$ 7.5, $100 \mathrm{mM} \mathrm{NaCl}, 2$ mM EDTA pH 8.0, 1\% NP-40, 20 mM sodium molybdate plus protease inhibitors as above) to prevent dissociation of $\mathrm{Hsp} 90$ from client proteins. $500 \mu \mathrm{g}$ lysate was mixed overnight with $0.5 \mu \mathrm{g}$ ErbB2 antibody and Protein A/G beads, washed four times with wash buffer (gentle lysis buffer without $\mathrm{NaCl}$ ) with protease inhibitors and boiled in 
2x Laemmli sample buffer. Proteins from $20 \mu \mathrm{g}$ total cell lysate (input) were analyzed alongside the immunoprecipitate by Western blotting.

Immunofluorescence: ADPKD cells $\left(1 \times 10^{4}\right.$ per well) were plated in 8-well chamber slides, serum starved for $24 \mathrm{~h}$ and treated for $48 \mathrm{~h}$ with $25 \mathrm{ng} / \mathrm{ml}$ EGF. Cells were fixed, permeabilized and blocked with $1 \%$ BSA. Cells were then incubated for $1 \mathrm{~h}$ with anti-Hsp90 antibody (Cell Signaling), washed with PBS and incubated for $1 \mathrm{~h}$ with FITC-conjugated secondary antibody. Slides were mounted with DAPI-containing mounting medium. Images were captured at 60x. Cultured metanephric kidneys were fixed in $4 \%$ paraformaldehyde and frozen sections were cut. For staining, sections were subjected to heat retrieval and were incubated with an antiPCNA antibody (Sigma) and with anti-mouse Texas Red (Jackson Immunoresearch).

Actin staining: Human ADPKD cells or mouse M-1 cortical collecting duct cells were plated in a 4-well chamber slide in 5\% FBS-containing medium. After $24 \mathrm{~h}$, the cells were treated with increasing concentrations of $\mathrm{H} 2-\mathrm{GMZ}$ for $16 \mathrm{~h}$. Cells were fixed in $4 \%$ paraformaldehyde and permeabilized using $0.2 \%$ Triton-X 100 . Cells were then incubated for 20 min with TRITCconjugated phalloidin, washed with PBS and mounted with DAPI-containing mounting medium. Images were captured at 10x (A) or 60x (B), using the same exposure settings for treated and untreated cells.

Cell migration assay: Human ADPKD cells were plated on a 12-well cell culture plate in $5 \%$ FBS + ITS medium and allowed to form a confluent monolayer. The monolayer was wounded by scratching it with a $\mathrm{P}-200$ pipette tip and the medium was changed to include increasing concentrations of H2-GMZ. Images of three different fields per well were captured at 10x magnification immediately after wounding and at 4, 8 and $24 \mathrm{~h}$ post-wounding. The area of the wound was measured at each time point using NIH Image J program. Percentage of wound closure was calculated by subtracting the area of the wound at any given time point from the 0 $\mathrm{h}$ wound area and expressing it as a percentage of the $0 \mathrm{~h}$ wound area.

Metanephric organ culture: $P k d 1^{m 1 B e i}$ mice were obtained from the Mutant Mouse Regional Resource Center (University of North Carolina, Chapel Hill, NC) and were stabilized onto a C57BL/6 background (>10 backcrosses). This mouse has a point mutation ( $T$ to $G$ at $9248 \mathrm{bp}$ ) that causes an $M$ to $R$ substitution affecting the first transmembrane domain of polycystin-1 (81). Mouse metanephric kidneys were cultured according to methods described previously $(67,82-84)$. Metanephroi were dissected from embryonic mice and placed on transparent Falcon $0.4 \mathrm{~mm}$ cell culture inserts. DMEM/F12 defined culture medium (supplemented with 2 $\mathrm{mM}$ L-glutamine, $10 \mathrm{mM}$ HEPES, $5 \mu \mathrm{g} / \mathrm{ml}$ insulin, $5 \mu \mathrm{g} / \mathrm{ml}$ transferrin, $2.8 \mathrm{nM}$ selenium, 25 $\mathrm{ng} / \mathrm{ml}$ prostaglandin E, $32 \mathrm{pg} / \mathrm{ml} \mathrm{T3}, 250 \mathrm{U} / \mathrm{ml}$ penicillin, and $250 \mu \mathrm{g} / \mathrm{ml}$ streptomycin) was added under the culture inserts, and organ cultures were maintained in a $37^{\circ} \mathrm{C}$ humidified $\mathrm{CO}_{2}$ incubator for up to 6 days. $100 \mu \mathrm{M}$ 8-Br-cAMP was added to induce cyst formation. This was followed by 1-5 $\mu \mathrm{M} \mathrm{H2-GMZ}$ or LND for three days. Upon culturing and approximately $24 \mathrm{~h}$ later (Day 1) and each day following (Days 2-5), kidneys were photographed using a $2 \mathrm{X}$ or $4 \mathrm{X}$ objective, and the images were acquired and quantified using the analySIS imaging program (Soft Imaging System). Fractional cyst area was calculated as total tubule dilation area divided by total kidney area.

Mouse strains and treatments: All animal protocols were approved and conducted in accordance with Laboratory Animal Resources of the University of Kansas Medical Center and Institutional Animal Care and Use Committee regulations. Pkd1 flox/flox:Pkhd1-Cre mice (73) 


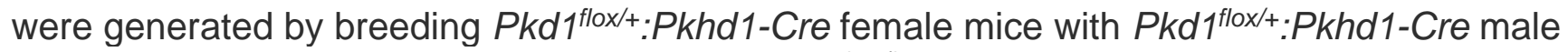
mice. H2-GMZ treatment was carried out on Pkd1 flox/flox:Pkhd1-Cre mice using daily intraperitoneal (i.p.) injections of $20 \mathrm{mg} / \mathrm{kg} \mathrm{H} 2-\mathrm{GMZ}$ from postnatal (PN) day 8 to 18.

\section{RESULTS}

\section{H2-GMZ inhibits CFTR-mediated $\mathrm{Cl}^{-}$secretion by ADPKD cells}

Lonidamine (LND) has been shown to bind directly to CFTR and inhibit CFTRdependent transepithelial anion currents across rat epididymal cells (48-50). As such, we were interested in testing the effectiveness of the derivative H2-GMZ as an inhibitor of CFTRmediated $\mathrm{Cl}^{-}$secreted by ADPKD cells. For this, confluent ADPKD cell monolayers were evaluated in Ussing chambers using short-circuit current assays in the presence of forskolin to stimulate $\mathrm{Cl}^{-}$secretion. The epithelial $\mathrm{Na}^{+}$channel ENaC was inhibited using benzamil to eliminate cation absorption. We found that $1 \mu \mathrm{M} \mathrm{H} 2-\mathrm{GMZ}$ effectively inhibited CFTR-mediated short-circuit currents within minutes (Fig. 1). Increasing concentrations of LND (up to $120 \mu \mathrm{M}$ ) did not have an effect, whereas addition of $\mathrm{H} 2-\mathrm{GMZ}$ after LND treatment, or alone, reduced the anion current significantly (Fig. 1C, D). Thus, H2-GMZ appears to be much more effective than LND in inhibiting CFTR-mediated $\mathrm{Cl}^{-}$secretion across ADPKD monolayers.

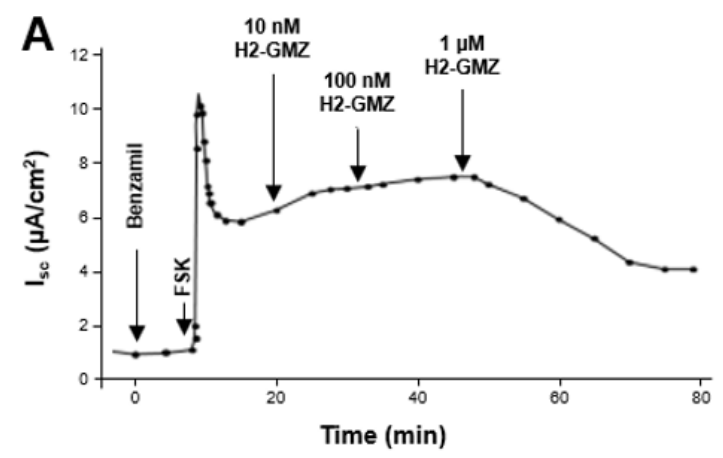

B
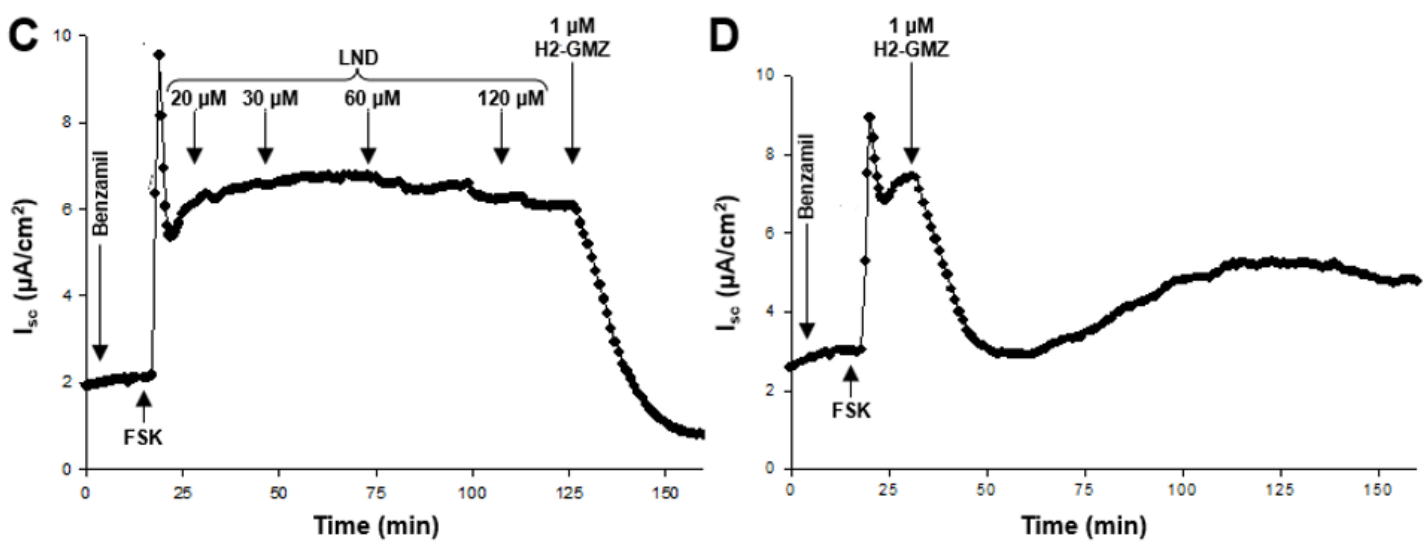

Fig. 1. H2-GMZ inhibits CFTR-mediated short-circuit current in ADPKD monolayers. A and B, Apical treatment with H2-GMZ inhibits forskolin-induced short-circuit current in ADPKD monolayers. Confluent monolayers of human ADPKD cells treated apically with benzamil, then forskolin to first block the ENaC channel and then induce CFTR-current. Increasing concentrations of H2-GMZ were added and the change in current recorded. The graph represents the average of four different monolayers from two ADPKD kidneys. *, the effect was statistically significant at $p<0.05$ as determined by ANOVA. C, Effect of LND on forskolin-generated current in ADPKD cells followed by $1 \mu \mathrm{M} \mathrm{H} 2-\mathrm{GMZ}$, or $\mathbf{D}$, with $1 \mu \mathrm{M}$ H2GMZ alone. 


\section{H2-GMZ inhibits cell proliferation in ADPKD cells}

ADPKD is a neoplastic disorder in which cyst-lining epithelial cells proliferate and secrete fluid into the lumen causing cyst expansion in kidney, liver and other organs. We were interested in examining whether H2-GMZ has an inhibitory effect on the proliferation of ADPKD cells since LND has proven to be an effective anti-proliferative, cancer chemotherapeutic agent. Initial studies with GMZ showed that it inhibits the proliferation of MCF-7 cells with an IC50 of $\sim 100 \mu \mathrm{M}$ (52). As shown in Fig. 2A, H2-GMZ inhibited the proliferation of ADPKD cells stimulated either with CAMP or EGF and assayed at $72 \mathrm{~h}$. This inhibition occurred in a dosedependent manner with an IC50 of 5-10 $\mu \mathrm{M}$. In contrast, the IC50 was close to $50 \mu \mathrm{M}$ in the presence of 5\% FBS (Fig. 2B). To analyze the effect of H2-GMZ on ADPKD cell proliferation at
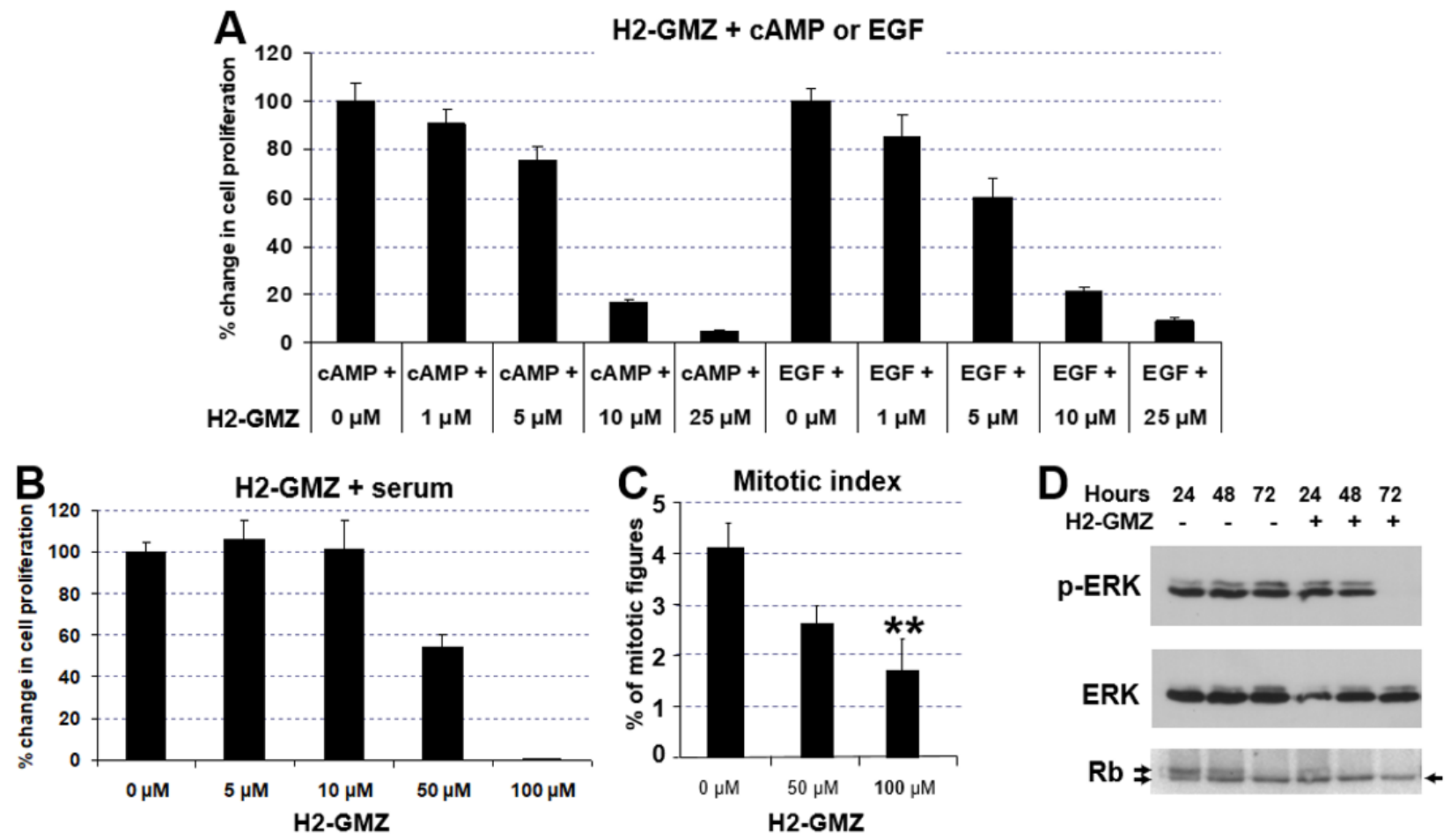

Fig. 2. Dose-dependent decrease in the proliferation of primary human ADPKD cells treated with H2-GMZ. A and B, Dose response of ADPKD cells stimulated with $100 \mu \mathrm{M}$ cAMP, $25 \mathrm{ng} / \mathrm{ml}$ EGF or $5 \%$ FBS and treated with $\mathrm{H} 2-\mathrm{GMZ}$. After 72 hours of treatment, MTT assays were performed. In each group, results were expressed as a percentage of the control group (not treated with H2-GMZ). The error bars indicate a standard error for $n=6$. C, ADPKD cells stimulated with $5 \%$ FBS and treated with H2-GMZ show a significant decrease in the number of mitotic figures. Cells were stained with DAPI to visualize the nuclei. Statistical analysis was done using One-way ANOVA and the Tukey HSD test for pair-wise comparisons. ${ }^{*}$ indicates $p<0.01$. D, Inhibition of p-ERK and hyperphosphorylated $\mathrm{Rb}$ in $\mathrm{H} 2-\mathrm{GMZ}$ treated ADPKD cells correlates with the inhibition of cell proliferation. In growing cells, there is a doublet of hyper- (upper) and hypo- or non-phosphorylated (lower) Rb (retinoblastoma) protein. H2-GMZ treatment decreased the levels of hyperphosphorylated $\mathrm{Rb}$ (upper arrow) consistent with decreased cell proliferation. Cytoplasmic extracts were prepared following 24,48 or 72 hours of $50 \mu \mathrm{M} \mathrm{H} 2-\mathrm{GMZ}$ treatment in the presence of serum and analyzed by Western blotting.

an earlier time point, we stained cells on chamber slides with the nuclear DAPI stain after treating for $16 \mathrm{~h}$ with $\mathrm{H} 2-\mathrm{GMZ}$. $50 \mu \mathrm{M} \mathrm{H} 2-\mathrm{GMZ}$ decreased the mitotic index in comparison to untreated controls, and $100 \mu \mathrm{M} \mathrm{H} 2-\mathrm{GMZ}$ was even more effective ( $\mathrm{p}<0.01$, Fig. $2 \mathrm{C})$. The results indicate that $\mathrm{H} 2-\mathrm{GMZ}$ effectively arrests the proliferation of ADPKD cystic cells in culture. The IC50 for inhibition of cell proliferation by LND was similar to that for H2-GMZ (Supplemental Fig. 1).

To determine the mechanism for inhibition of cell proliferation, we tested the effect of $\mathrm{H} 2-\mathrm{GMZ}$ on the levels of phosphorylated ERK ( $p$-ERK). ADPKD cells were treated for 24, 48 or $72 \mathrm{~h}$ with $50 \mu \mathrm{M} \mathrm{H} 2-\mathrm{GMZ}$. Western blotting with antibodies against $\mathrm{p}$-ERK and total ERK 
suggested that H2-GMZ-mediated inhibition of cell proliferation occurs at least in part through inhibition of the MEK-ERK pathway (Fig. 2D), which is consistent with previous work that showed that cAMP-driven ERK activation stimulates ADPKD cell proliferation $(13,14,19,71)$ Hyperphosphorylated Rb levels also decreased with H2-GMZ treatment (Fig. 2D, upper band), consistent with inhibition of cell proliferation. Since $\mathrm{Rb}$ is an important effector of cell cycle progression, the decrease in hyperphosphorylated $\mathrm{Rb}$ as well as $\mathrm{p}$-ERK could contribute to the inhibition of cell proliferation by H2-GMZ.

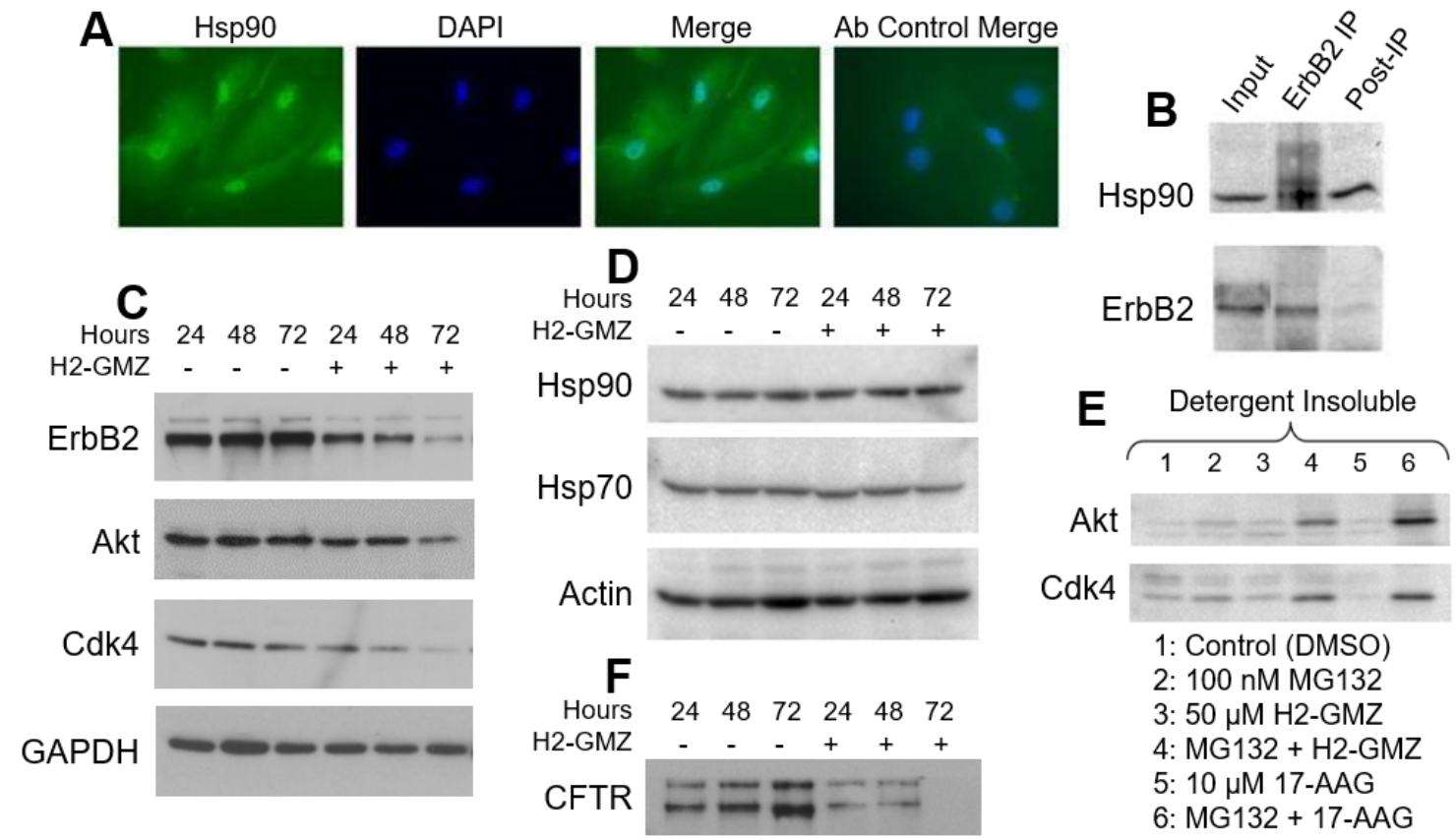

Fig. 3. H2-GMZ blocks Hsp90 function in primary human ADPKD cells. A, ADPKD cells were stained with anti-Hsp90 antibody (green) to show the presence of Hsp90 in the cytoplasm and nucleus. Cells were counterstained with the nuclear stain DAPI (blue). The control well was incubated with FITCconjugated secondary antibody alone. B, Hsp90 and client protein ErbB2 remain associated in ADPKD cells. ErbB2 was immunoprecipitated from ADPKD cell lysate and the association with Hsp90 was determined by Western blotting. C and D, H2-GMZ treatment decreases Hsp90 client protein levels. ADPKD cells were treated for 24,48 or 27 hours with $50 \mu \mathrm{M} \mathrm{H} 2-\mathrm{GMZ}$ and analyzed by Western blotting. GAPDH and Actin served as internal controls. E, H2-GMZ targets Hsp90 client proteins for degradation via the proteasome pathway. ADPKD cells treated with H2-GMZ for 24 hours in the presence or absence of MG132, a proteasome inhibitor, were lysed in buffer containing Triton-X 100 and the insoluble material was pelleted and analyzed by Western blotting. 17-AAG was used as a positive control for the inhibition of the proteasomal pathway. F, H2-GMZ treatment decreases CFTR protein levels. All results are representative of three independent experiments with cells from three different ADPKD kidneys.

\section{H2-GMZ decreases Hsp90 client protein levels in ADPKD cells}

Previous studies had shown that GMZ inhibits the Hsp90 pathway in Sertoli cells $(52,53)$. Since the molecular chaperone Hsp90 has been shown to play an important role in maintaining the abnormal proliferative state in various tumor types, we sought to explore the status of Hsp90 in ADPKD cells and whether H2-GMZ inhibited the Hsp90 pathway in these cells. The presence of Hsp90 in ADPKD cells was checked by immunofluorescence, showing localization in the cytoplasm and nucleus (Fig. 3A). The presence of Hsp90 in the nucleus has been well-documented $(56,85)$. To show that client proteins interact with Hsp90 in ADPKD cells, we conducted pull-down experiments with ErbB2 as a representative Hsp90 client protein that may be relevant to ADPKD progression (64). As shown in Fig. 3B, the endogenous proteins, Hsp90 and ErbB2, co-immunoprecipitated from ADPKD cell lysates.

To determine whether H2-GMZ affects the levels of other Hsp90 pathway proteins, ADPKD cells were treated for various times with $50 \mu \mathrm{M} \mathrm{H} 2-\mathrm{GMZ}$ and protein levels were determined by Western blotting. H2-GMZ treatment decreased the amounts of the known client proteins ErbB2, Akt and Cdk4, all of which regulate cell proliferation (Fig. 3C). Treatment with H2-GMZ did not increase the levels of Hsp90 or Hsp70 (Fig. 3D). Thus, H2-GMZ appears 
to affect Hsp90 client proteins without eliciting the heat-shock response, a highly desirable outcome for an Hsp90 pathway inhibitor.

\section{H2-GMZ treatment leads to degradation of Hsp90 client proteins through the proteasome pathway}

Hsp90 inhibitors such as 17-AAG interfere with the chaperone function of Hsp90 (86), thus targeting client proteins to the ubiquitin-mediated proteasomal degradation pathway. Simultaneous inhibition of Hsp90 function and the proteasome pathway would result in the accumulation of ubiquitinated client proteins in the detergent-insoluble fraction of the cell lysate (87). To check whether H2-GMZ targets Hsp90 client proteins for degradation via the proteasome pathway, we treated primary human ADPKD cells with $\mathrm{H} 2-\mathrm{GMZ}$ for $24 \mathrm{~h}$ in the presence or absence of the proteasome inhibitor MG132 and determined the levels of Hsp90 client proteins in the detergent (Triton-X 100)-soluble and insoluble fractions from the cell lysate. Fig. 3E shows the accumulation of representative client proteins Akt and Cdk4 in the detergent-insoluble fraction following treatment with H2-GMZ and MG132 (Lane 4). 17-AAG served as positive control (Lane 6).

In our experiments, $\mathrm{H} 2-\mathrm{GMZ}$ appeared to inhibit key signaling proteins that require Hsp90 for maturation or activity. Newly synthesized CFTR protein remains dependent on $\mathrm{Hsp90}$ for functional maturation in the ER, and the Hsp90 inhibitor geldanamycin leads to accelerated degradation of CFTR protein (88). This prompted us to determine the status of CFTR in ADPKD cells following H2-GMZ treatment. We found that $\mathrm{H} 2-\mathrm{GMZ}$ treatment led to a robust inhibition of CFTR protein levels in a time-dependent manner (Fig. 3F). Thus H2-GMZ seems to affect CFTR in multiple ways, as a direct channel inhibitor and by causing a decrease in CFTR protein. As such, H2-GMZ should be an efficient inhibitor of $\mathrm{Cl}^{-}$-dependent fluid secretion by ADPKD cyst-lining cells.

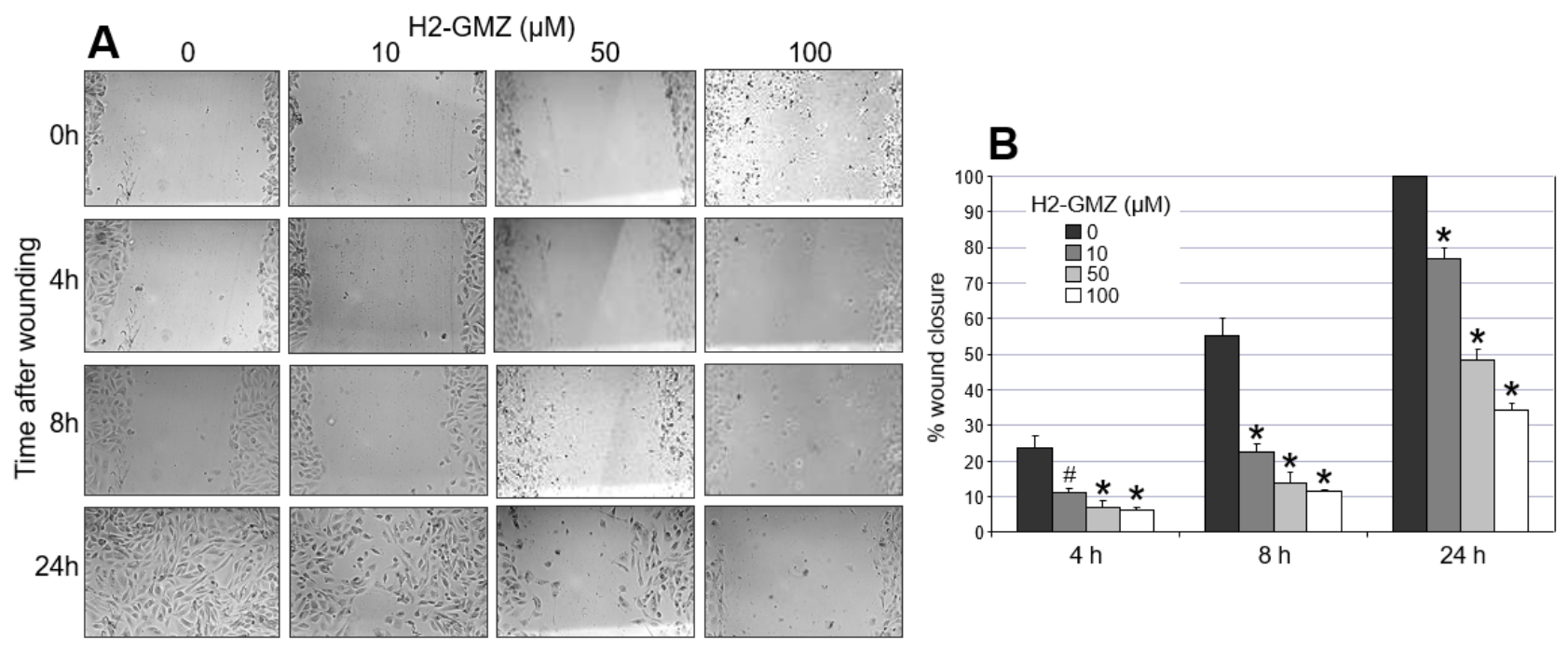

Fig. 4. H2-GMZ treatment inhibits cell migration. A, Confluent monolayers of human ADPKD cells were scratched with a P20 pipette tip, then treated with increasing concentrations of $\mathrm{H} 2-\mathrm{GMZ}$. Wound images were captured at $10 x$ magnification immediately after wounding and at 4,8 and 24 hours post-wounding. B, Percentage of wound closure was calculated by subtracting the area of the wound at any given time point from the $0 \mathrm{~h}$ wound area expressed as a percentage of the $0 \mathrm{~h}$ wound area. Statistical analysis was done to compare the H2-GMZ-treated cells to untreated cells at each time point using One-way ANOVA and the Tukey HSD test for pair-wise comparisons. \# : $p<0.05,{ }^{*}: p<0.01$. The assay was done in triplicate.

\section{H2-GMZ inhibits ADPKD cell migration}

ADPKD cells exhibit significantly higher chemotactic migration in response to EGF compared to normal cells (89). Hence blocking the abnormal motility of ADPKD cells could 
have a normalizing therapeutic effect. To examine whether H2-GMZ inhibits ADPKD cell motility, we performed a cell migration/wound-healing assay. As little as $10 \mu \mathrm{M} \mathrm{H} 2-\mathrm{GMZ}$ significantly inhibited the migration of ADPKD cells in $4 \mathrm{~h}$ (Fig. 4A, B). The inhibition lasted up to 24 hours and was dose dependent.

Actin bundling is essential for maintaining cell structure, cytoskeletal dynamics and cell motility. In the original screen for proteins binding to GMZ, Tash and colleagues (52) identified the eukaryotic translation elongation factor eEF1A1 as binding strongly to GMZ. eEF1A regulates actin bundling and organization separately from its function in translation $(90,91)$. Since GMZ did not appear to inhibit nucleotide binding by eEF1A1, they hypothesized that GMZ might inhibit actin bundling. To determine whether H2-GMZ can inhibit actin cytoskeletal organization, human ADPKD cells and mouse M-1 cells were stained with phalloidin conjugated with the fluorophore TRITC (Fig. 5A, B). Untreated cells exhibited leading edges (lamellipodia) characteristic of migrating cells, whereas H2-GMZ-treated cells were smaller, without leading edges and with less filamentous actin (F-actin), consistent with an effect on cell motility (Fig. 4B).

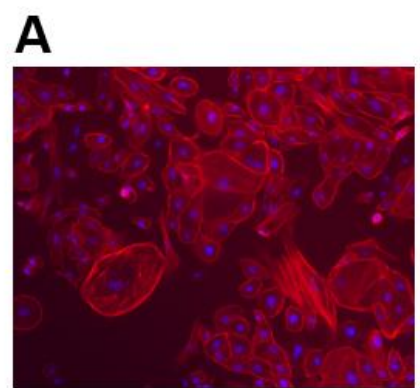

$0 \mu \mathrm{M}$

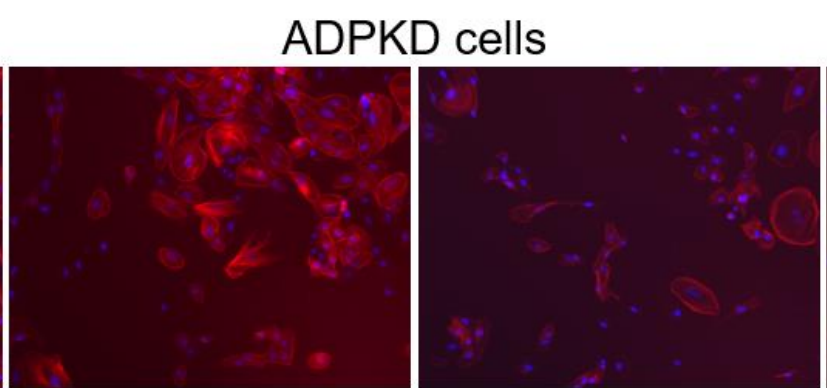

$10 \mu \mathrm{M}$

H2-GMZ

$50 \mu \mathrm{M}$

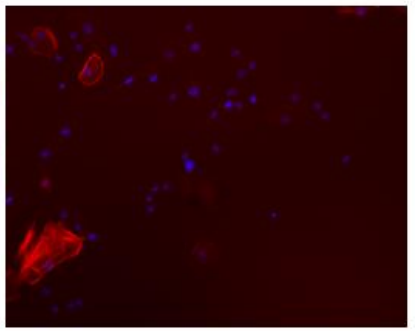

$100 \mu \mathrm{M}$

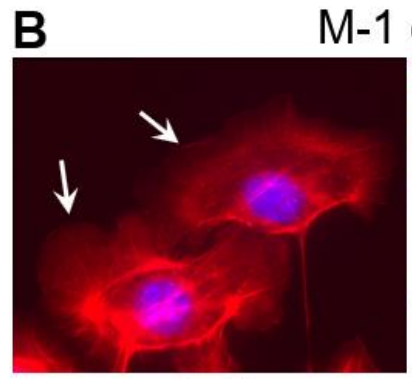

$0 \mu \mathrm{M}$
M-1 cells

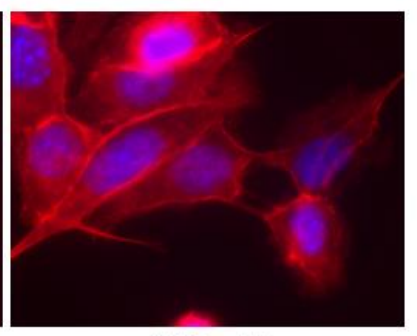

H2-GMZ
$100 \mu \mathrm{M}$

Fig. 5. H2-GMZ treatment affects the actin cytoskeleton. A and B, Human ADPKD cells or mouse M-1 cortical collecting duct cells were treated with increasing concentrations of $\mathrm{H} 2-\mathrm{GMZ}$ and stained with phalloidin. Images were captured at $10 \mathrm{x}$ (A) or 60x (B) using the same exposure settings for treated and untreated cells. Red color shows phalloidin bound to actin filaments in the cell. Blue indicates DAPI-stained nuclei. The assay was done in triplicate.

\section{H2-GMZ treatment decreases cystic index in metanephric organ culture}

We previously showed that CFTR channels are functional in embryonic kidneys and are required for cAMP-driven cyst-like tubule expansion (67). Since H2-GMZ blocked both cell proliferation and CFTR-mediated fluid secretion in ADPKD cells, we examined the effectiveness of $\mathrm{H} 2-\mathrm{GMZ}$ in inhibiting cAMP-dependent cyst growth and enlargement in mouse embryonic kidneys in organ culture. For this, we used kidneys from Pkd1m1Bei +/- or -/- embryos (81). As shown in Figure 6, $5 \mu \mathrm{M} \mathrm{H} 2-\mathrm{GMZ}$ significantly inhibited cyst formation.

H2-GMZ was also effective when it was added a day after cyst initiation (Supplemental Fig. 2) and was partially effective when it was washed out of the medium following a $24 \mathrm{~h}$ treatment period (Supplemental Fig. 3). LND also inhibited cyst growth in $P k d 1^{m 1 B e i}+/-$ 
metanephric kidneys (Supplemental Fig. 4) but did not appear to be as effective as the same dose of H2-GMZ. Five $\mu \mathrm{M}$ LND did not inhibit cyst growth in Pkd1 ${ }^{\mathrm{m} 1 \mathrm{Bei}}$-/- metanephric kidneys (data not shown).

Next, we stained H2-GMZ treated metanephric kidneys for PCNA, a marker for cell proliferation. There was a marked decrease in the intensity of PCNA staining in treated kidneys compared to controls (Supplemental Fig. 5A, B). As expected for growing embryonic kidneys, there were many brightly stained vesicles and S-shaped bodies visible in the untreated kidney while there were very few in the H2-GMZ treated kidney.

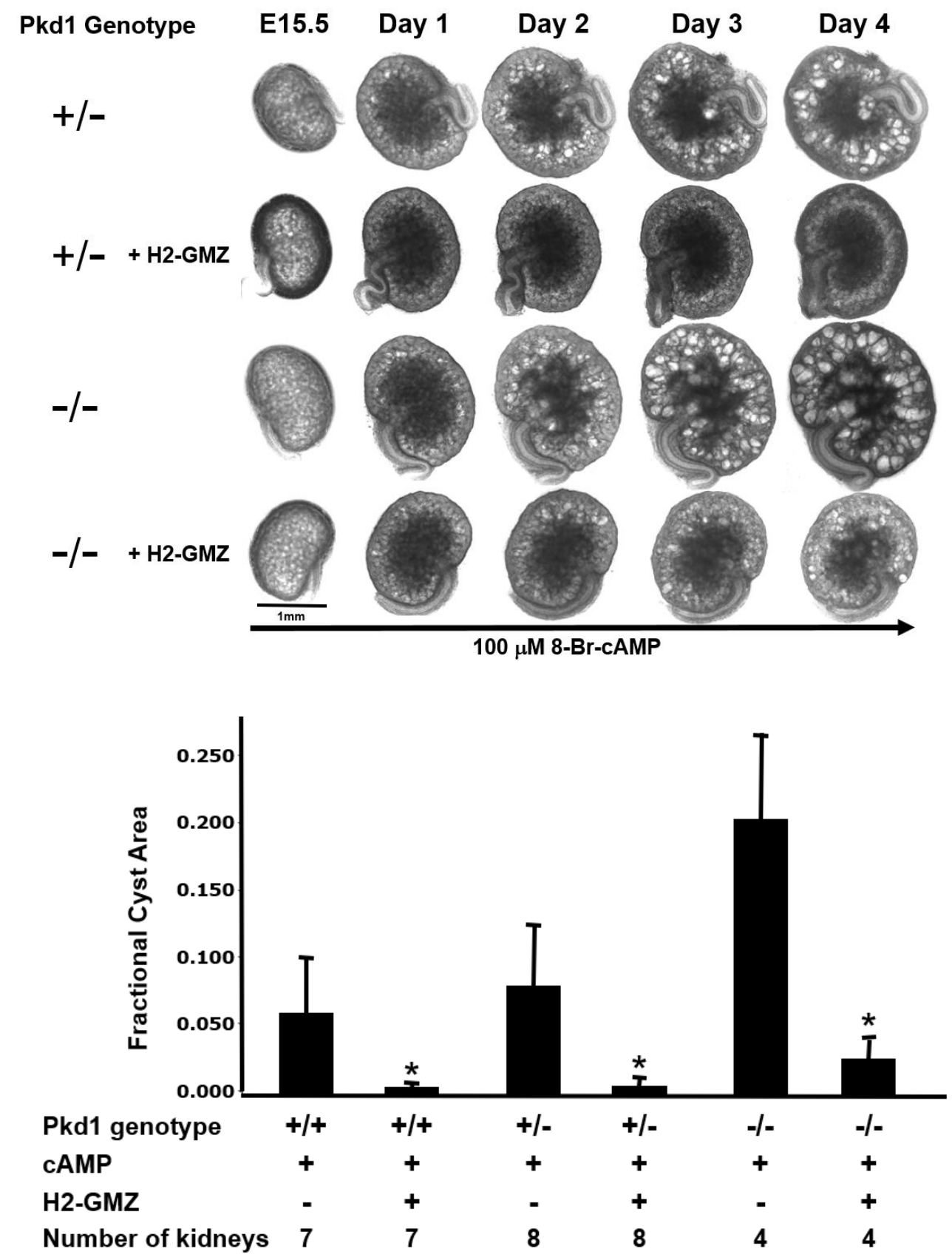

Fig. 6. H2-GMZ treatment reduces the cyst burden in cAMP-treated metanephric kidneys. Embryonic day15.5 mouse kidneys from Pkd1 +/- and -/- mice were plated on Transwell membranes and treated with $100 \mu \mathrm{M}$ cAMP with or without $5 \mu \mathrm{M}$ H2GMZ for four days. H2-GMZ treatment reduced the cystic index of treated kidneys. Fractional cyst area is the total area of all the cysts per kidney represented as a fraction of the total area of the kidney. The number of kidneys of each genotype is listed. ${ }^{*}$, the effect was statistically significant at $p<0.01$ as determined by Student's t-test. 


\section{H2-GMZ treatment decreases cyst progression in vivo in a Pkd1 mouse model}

To determine the effects of $\mathrm{H} 2-\mathrm{GMZ}$ in vivo, treatment was carried out on Pkd1 flox/flox: Pkhd1-Cre mice using daily i.p. injections of $20 \mathrm{mg} / \mathrm{kg} \mathrm{H} 2-\mathrm{GMZ}$ from postnatal day 8 (PN8) to 18 (PN18). Mice treated with H2-GMZ had significantly smaller kidneys and increased renal parenchyma (Fig. 7A), reduced cystic index (Fig. 7B), decreased kidney weight to body weight (KW/BW), and improved blood urea nitrogen (BUN) levels (Fig. 7B). Survival studies (Fig. 7C) showed significantly longer survival for H2-GMZ-treated mice (Control vs H2-GMZ: $28.8 \pm 5$ vs $67.8 \pm 23 ; \mathrm{p}<0.01$ ) indicating that $\mathrm{H} 2-\mathrm{GMZ}$ may be effective in prolonging renal function.

A

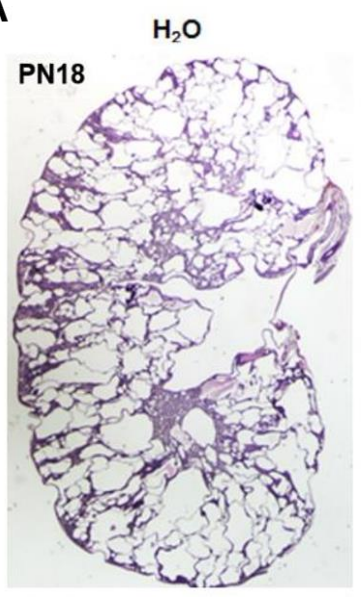

H2-GMZ

PN18

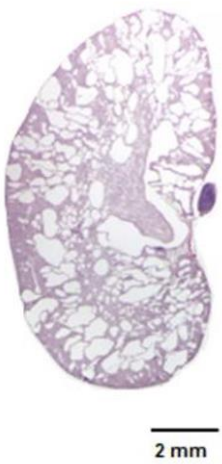

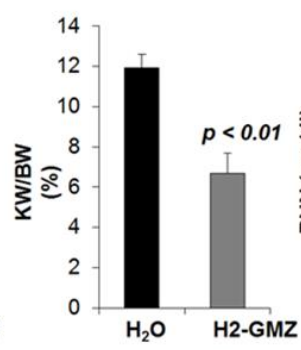

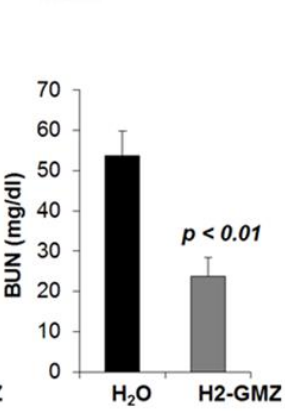

C

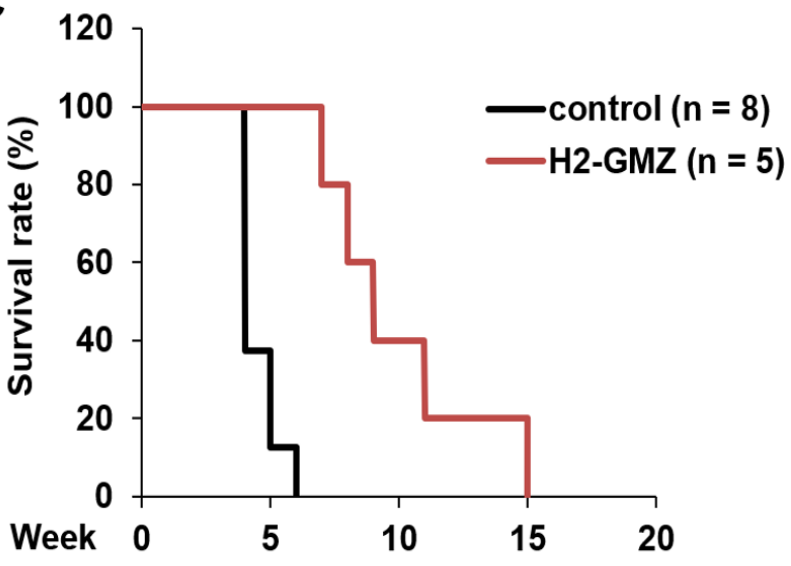

Fig. 7. H2-GMZ treatment decreases cystic burden in vivo in a $\boldsymbol{P k d 1}$ mouse model. H2-GMZ treatment was carried out on $P k d 1^{\text {floxfflox}: P k h d 1-C r e ~ m i c e ~ u s i n g ~ d a i l y ~ i . p . ~}$ injections of $20 \mathrm{mg} / \mathrm{kg} \mathrm{H} 2-\mathrm{GMZ}$ from postnatal day 8 to 18. $\mathbf{A}$ and $\mathbf{B}$, Mice treated with H2-GMZ had a significantly reduced cystic index, smaller kidneys and increased renal parenchyma, decreased kidney weight to body weight (KW/BW) and improved blood urea nitrogen (BUN) levels. C, Survival studies showed significantly longer survival for $\mathrm{H} 2-\mathrm{GMZ}$-treated mice (Control vs H2GMZ: $28.8 \pm 5$ vs $67.8 \pm 23 ; p<0.01)$.

\section{DISCUSSION}

In this study, we investigated the potential of a new class of drugs for ADPKD. We provide evidence that the novel indazole carboxylic acid derivative, $\mathrm{H} 2-\mathrm{GMZ}$, is effective in inhibiting fluid secretion and cell proliferation in human ADPKD cells, mouse metanephric kidneys and in a rapidly progressive mouse model of PKD. To further understand the mechanism of action of H2-GMZ, we explored its effects on the activities of CFTR, Hsp90, and eEF1A1, three proteins through which $\mathrm{H} 2-\mathrm{GMZ}$ appears to mediate its actions in the cell. Human ADPKD cell monolayers responded to H2-GMZ treatment with decreased CFTRmediated anion current. We also found that H2-GMZ decreased the levels of a number of Hsp90 client proteins, including CFTR, and targeted them for degradation through the ubiquitin-proteasome pathway. Many of these Hsp90 client proteins are required for cell growth and proliferation. H2-GMZ also inhibited the motility of ADPKD cells and decreased F-actin levels, consistent with an inhibition of the actin-bundling properties of eEF1A1. Furthermore, low micromolar concentrations of $\mathrm{H} 2-\mathrm{GMZ}$ were effective in inhibiting cyst formation in a Pkd1 mutant mouse metanephric organ culture model in which a number of processes mediate the growth and enlargement of cysts in response to cAMP (67). Finally, daily injection of H2-GMZ 
in a postnatal $P k d 1$ mouse model showed inhibition of cystogenesis and increased survival indicating that H2-GMZ effectively targets the kidney in vivo.

Hsp90 function is critical for protein folding and function in eukaryotic cells. Protein molecules exist in a crowded state in the cell, which favors inter-molecular interactions but risks misfolding and aggregation (56,57). Hsp90 uses energy derived from ATP to promote the protein conformation required for proper functioning. In various neoplastic disorders, Hsp90 and its client proteins are overexpressed and/or hyperactive (92). This leads to increased signaling and uncontrolled cell growth and division. Targeting $\mathrm{Hsp90}$ to reduce its activity has proven to be beneficial in curbing the growth of many tumors $(61,63,86,92-94)$. The Hsp90 inhibitors STA-2842 and STA-9090 (ganetespib) have been shown to be effective in reducing cyst size and disease progression in mouse models PKD (75-77). As ADPKD has many of the characteristics of a neoplastic disorder (95), we believe this approach may be useful in treating patients with ADPKD.

In ADPKD, renal epithelial cysts grow and enlarge through a process of abnormal cell proliferation and increased fluid secretion. Each cyst could be considered a fluid-filled tumor (96). Apical $\mathrm{Cl}^{-}$transport by CFTR drives net fluid secretion into the cyst lumen in response to cAMP $(12,16,97,98)$. Cyst-lining cells are poorly differentiated, and express elevated protooncogenes (99). Overexpression of oncogenes c-myc, rasT24, and SV40 large T antigen leads to PKD in transgenic mouse models (100-102). A key pathway that is abnormally activated in PKD is the MEK-ERK pathway, as seen also in many types of cancer $(13,19,71-73,103,104)$. In addition, there is evidence for activation of the EGF family receptors, IGF receptors and $\beta$ catenin in many types of cancer as well as PKD $(64,74,105,106)$. A number of these pathways need Hsp90 for sustained activation. There may be higher than normal levels of certain proteins in ADPKD cells that would utilize Hsp90 for their continued aberrant function. For example, the EGFR family receptor ErbB2 (Her2), an Hsp90 client protein, is overexpressed in PKD $(64,65)$. Cyst-lining renal epithelial cells also overexpress CFTR $(97,98,107)$. For these reasons we expect that an inhibitor of the Hsp90 pathway would preferentially target the cystic epithelium rather than the normal renal parenchyma.

$\mathrm{H} 2-\mathrm{GMZ}$ is a novel derivative of the anti-cancer drug lonidamine (LND), used to treat various types of cancer (47,108-110). LND is known to inhibit cellular glucose metabolism, possibly by its effect on mitochondrial hexokinase $(110,111)$. Drug resistant breast cancer cells and malignant glioma cells were found to be especially sensitive to LND $(110,111)$. In addition, LND inhibits CFTR activity in cultured epididymal cells, presumably by direct binding to the pore of the channel (48-50). While the exact mechanism of anti-tumor activity of LND is unknown, it is most likely a combination of the activities mentioned above and possibly additional activities. LND was originally described as an anti-spermatogenic drug (112). In an effort to develop better male contraceptives, various analogs of LND were synthesized among which GMZ showed the greatest potency and the least side effects $(52,55)$. Since PKD is a chronic condition that might require a lifetime of therapy, a drug with excellent safety and toxicity profiles would be the ideal candidate for PKD therapy. In animal studies, GMZ was very well tolerated (55).

In studies to understand the mechanism of action of $\mathrm{GMZ}$, it was observed that $\mathrm{GMZ}$ affects two proteins: the constitutive isoform of Hsp90, Hsp90AB1, and the eukaryotic elongation factor eEF1A1 (52). The mechanism by which GMZ inhibits Hsp90 is currently being investigated. Neither geldanamycin (which binds to the N-terminus of Hsp90) nor a novobiocin derivative (which binds the C-terminus) could compete with GMZ for Hsp90 binding (52). Therefore, it is possible that GMZ binds to a different site on Hsp90 or that it binds one of the co-chaperones in the Hsp90 super complex. In fact, subsequent studies have demonstrated that the Hsp90-cdc37 chaperone complex was disrupted following H2-GMZ 
treatment in the ErbB2-overexpressing cancer cell line SKBr3 (53). Hsp90 inhibition by GMZ was also confirmed by a decrease in client proteins ErbB2 and Akt $(52,53)$.

In testing the effect of H2-GMZ on Hsp90-mediated activation of key signaling proteins, we found that H2-GMZ treatment effectively decreased ErbB2 and Akt. ErbB2 (Her2) is known to be upregulated in ADPKD cells compared to normal renal epithelial cells and treatment with ErbB2 inhibitors was found to slow cyst growth in a mouse model of ADPKD (64). ADPKD cyst-lining epithelial cells exhibit misregulation of the PI3K-Akt-mTOR pathway $(69,113)$. The cyclin-dependent kinase Cdk4 is an Hsp90 client protein which phosphorylates retinoblastoma protein $(\mathrm{Rb})$ during the $\mathrm{G} 1$ phase of the cell cycle. The H2-GMZ mediated decrease in Cdk4 and hyperphosphorylated $\mathrm{Rb}$ could contribute to the observed decrease in cell proliferation. Consistent with $\mathrm{H} 2-\mathrm{GMZ}$ being an Hsp90 inhibitor, we showed that the unfolded client proteins were directed to the proteasome pathway for degradation.

One of the Hsp90 client proteins, the $\mathrm{Cl}^{-}$channel CFTR, plays an important role in the pathogenesis of ADPKD by mediating fluid secretion into the cyst lumen $(67,114)$, and CFTR inhibitors have proven effective in reducing cyst growth (66). We found that CFTR secretion decreases rapidly following treatment with H2-GMZ. Furthermore, CFTR protein levels decrease markedly 24 to 72 hours after H2-GMZ treatment. Since LND directly binds to and blocks CFTR, it is possible that H2-GMZ acts similarly. Thus H2-GMZ could be inhibiting CFTR channel activity via direct binding and also indirectly through Hsp90, making this drug an especially attractive candidate for ADPKD therapy.

ADPKD cell motility and migration could be involved in cyst formation and PKD progression since ADPKD cells as a monolayer on solid support migrate faster than normal cells to achieve wound closure (89). The integrity of the actin cytoskeleton is critically important to the ability of cells to migrate. It is known that LND significantly inhibits endothelial cell migration and invasiveness (115). LND treatment caused the disappearance of actin stress fibers and rearrangement of intermediate filaments and microtubules (116). We found that $\mathrm{H} 2-$ GMZ treatment effectively blocked ADPKD cell migration, perhaps by its effect on eEF1A1 (52). eEF1A1 is essential for regulation of the actin cytoskeleton $(91,117)$. Previous experiments showed that GMZ does not affect the GDP/GTP nucleotide binding properties of eEF1A1, which are required for it to mediate elongation during translation (52). Therefore it was postulated that GMZ might inhibit the bundling of F-actin by eEF1A1, a function separate from its role in protein translation (91). Our results indicate that H2-GMZ might disrupt cell migration by inhibiting actin polymerization. It is also possible that $\mathrm{H} 2-\mathrm{GMZ}$ could mediate its effect on cell migration independent of eEF1A1.

A drug like H2-GMZ with low toxicity and multiple cellular targets would be ideal for PKD treatment. One of the drawbacks of traditional Hsp90 inhibitors such as geldanamycin derivatives is the compensatory induction of Hsp90 and Hsp70 (118-120) thus reducing their effectiveness over time. In our studies, H2-GMZ did not induce Hsp90 or Hsp70 even after 72 hours of treatment. This lack of a heat shock response in treated cells could make the drug more effective in targeting the Hsp90 machinery. While H2-GMZ was explored as a potential male contraceptive, its anti-spermatogenic effect may not be considered a drawback for every male patient, or for female patients. Depending on the stage of the disease and the age and health of the patient, the long-term advantages may outweigh this potential disadvantage, thus justifying the use of $\mathrm{H} 2-\mathrm{GMZ}$ or other lonidamine derivatives in the treatment of ADPKD, although an effort to develop $\mathrm{H} 2-\mathrm{GMZ}$ analogs without male reproductive effects would be a worthwhile goal of future studies. Ultimately, the ideal treatment for PKD may be a combination of therapies in low tolerable doses that hit multiple critical targets including both cell proliferation and fluid secretion to slow cyst growth and enlargement and to preserve kidney function over the long term. 


\section{ACKNOWLEDGEMENTS}

Supported by grants from the KU Institute for Advancing Medical Innovation (IAMI), NIH (P30 DK106912) and PKD Foundation to JPC, NIH (R01 DK081579) to DPW, and the PKD Biomarkers, Biomaterials, and Cellular Models Core of the Kansas PKD Research and Translation Core Center (U54 DK126126). The authors thank Dr. Peter Igarashi and Dr. Stefan Somlo for the Pkd1 floxflox: Pkhd1-Cre mice.

\section{REFERENCES}

1. Yu, A. S. L., El-Ters, M., and Winklhofer, F. T. (2015) Clinical Trials in Autosomal Dominant Polycystic Kidney Disease. in Polycystic Kidney Disease (Li, X. ed.), Brisbane (AU). Chapter 6

2. Bergmann, C., Guay-Woodford, L. M., Harris, P. C., Horie, S., Peters, D. J. M., and Torres, V. E. (2018) Polycystic kidney disease. Nat Rev Dis Primers 4, 50

3. Cornec-Le Gall, E., Alam, A., and Perrone, R. D. (2019) Autosomal dominant polycystic kidney disease. Lancet 393, 919-935

4. Lanktree, M. B., Haghighi, A., Guiard, E., lliuta, I. A., Song, X., Harris, P. C., Paterson, A. D., and Pei, Y. (2018) Prevalence Estimates of Polycystic Kidney and Liver Disease by Population Sequencing. J Am Soc Nephrol 29, 2593-2600

5. Antignac, C., Calvet, J. P., Germino, G. G., Grantham, J. J., Guay-Woodford, L. M., Harris, P. C., Hildebrandt, F., Peters, D. J., Somlo, S., Torres, V. E., Walz, G., Zhou, J., and Yu, A. S. (2015) The Future of Polycystic Kidney Disease Research--As Seen By the 12 Kaplan Awardees. J Am Soc Nephrol 26, 2081-2095

6. Grantham, J. J., and Torres, V. E. (2016) The importance of total kidney volume in evaluating progression of polycystic kidney disease. Nat Rev Nephrol 12, 667-677

7. Sautenet, B., Cho, Y., Gutman, T., Rangan, G., Ong, A., Chapman, A. B., Ahn, C., Coolican, H., Tze-Wah Kao, J., Fowler, K., Gansevoort, R. T., Geneste, C., Perrone, R. D., Harris, T., Torres, V. E., Pei, Y., Craig, J. C., Tong, A.; SONG-PKD Initiative. (2020) Range and Variability of Outcomes Reported in Randomized Trials Conducted in Patients With Polycystic Kidney Disease: A Systematic Review. Am J Kidney Dis. 76(2), 213-223

8. Lanktree, M. B., and Chapman, A. B. (2017) New treatment paradigms for ADPKD: moving towards precision medicine. Nature Revs Nephrol 13, 750-768

9. Schrier, R. W. (2016) ACE inhibitors, left ventricular mass and renal cyst growth in ADPKD. Pharmacol Res 114, 166-168

10. Grantham, J. J., Geiser, J. L., and Evan, A. P. (1987) Cyst formation and growth in autosomal dominant polycystic kidney disease. Kidney Int 31, 1145-1152

11. Ye, M., and Grantham, J. J. (1993) The secretion of fluid by renal cysts from patients with autosomal dominant polycystic kidney disease. N Engl J Med 329, 310-313

12. Reif, G. A. and Wallace, D. P. (2019) ADPKD cell proliferation and Cl-dependent fluid secretion. Methods Cell Biol 153, 69-92

13. Yamaguchi, T., Pelling, J. C., Ramaswamy, N. T., Eppler, J. W., Wallace, D. P., Nagao, S., Rome, L. A., Sullivan, L. P., and Grantham, J. J. (2000) cAMP stimulates the in vitro proliferation of renal cyst epithelial cells by activating the extracellular signal-regulated kinase pathway. Kidney Int 57, 1460-1471 
14. Yamaguchi, T., Nagao, S., Wallace, D. P., Belibi, F. A., Cowley, B. D., Pelling, J. C., and Grantham, J. J. (2003) Cyclic AMP activates B-Raf and ERK in cyst epithelial cells from autosomal-dominant polycystic kidneys. Kidney Int 63, 1983-1994

15. Belibi, F. A., Reif, G., Wallace, D. P., Yamaguchi, T., Olsen, L., Li, H., Helmkamp, G. M., Jr., and Grantham, J. J. (2004) Cyclic AMP promotes growth and secretion in human polycystic kidney epithelial cells. Kidney Int 66, 964-973

16. Wallace, D. P. (2011) Cyclic AMP-mediated cyst expansion. Biochim Biophys Acta $1812,1291-1300$

17. Sussman, C. R., Wang, X., Chebib, F. T., and Torres, V. E. (2020) Modulation of polycystic kidney disease by G-protein coupled receptors and cyclic AMP signaling. Cell Signal 72, 109649

18. Rajagopal, M., and Wallace, D. P. (2015) Chloride secretion by renal collecting ducts. Curr Opin Nephrol Hypertens 24(5), 444-449

19. Yamaguchi, T., Wallace, D. P., Magenheimer, B. S., Hempson, S. J., Grantham, J. J., and Calvet, J. P. (2004) Calcium restriction allows cAMP activation of the B-Raf/ERK pathway, switching cells to a cAMP-dependent growth-stimulated phenotype. J Biol Chem 279, 40419-40430

20. Yamaguchi, T., Hempson, S. J., Reif, G. A., Hedge, A. M., and Wallace, D. P. (2006) Calcium restores a normal proliferation phenotype in human polycystic kidney disease epithelial cells. J Am Soc Nephrol 17, 178-187

21. Liu, Y., Dai, B., Fu, L., Jia, J., and Mei, C. (2010) Rosiglitazone inhibits cell proliferation by inducing G1 cell cycle arrest and apoptosis in ADPKD cyst-lining epithelia cells. Basic Clin Pharmacol Toxicol 106, 523-530

22. Buchholz, B., Klanke, B., Schley, G., Bollag, G., Tsai, J., Kroening, S., Yoshihara, D., Wallace, D. P., Kraenzlin, B., Gretz, N., Hirth, P., Eckardt, K. U., and Bernhardt, W. M. (2011) The Raf kinase inhibitor PLX5568 slows cyst proliferation in rat polycystic kidney disease but promotes renal and hepatic fibrosis. Nephrol Dial Transplant 26, 3458-3465

23. Bukanov, N. O., Moreno, S. E., Natoli, T. A., Rogers, K. A., Smith, L. A., Ledbetter, S. R., Oumata, N., Galons, H., Meijer, L., and Ibraghimov-Beskrovnaya, O. (2012) CDK inhibitors R-roscovitine and S-CR8 effectively block renal and hepatic cystogenesis in an orthologous model of ADPKD. Cell Cycle 11, 4040-4046

24. Shillingford, J. M., Leamon, C. P., Vlahov, I. R., and Weimbs, T. (2012) Folateconjugated rapamycin slows progression of polycystic kidney disease. J Am Soc Nephrol 23, 1674-1681

25. Caroli, A., Perico, N., Perna, A., Antiga, L., Brambilla, P., Pisani, A., Visciano, B., Imbriaco, M., Messa, P., Cerutti, R., Dugo, M., Cancian, L., Buongiorno, E., De Pascalis, A., Gaspari, F., Carrara, F., Rubis, N., Prandini, S., Remuzzi, A., Remuzzi, G., Ruggenenti, P.; ALADIN Study Group (2013) Effect of longacting somatostatin analogue on kidney and cyst growth in autosomal dominant polycystic kidney disease (ALADIN): a randomised, placebo-controlled, multicentre trial. Lancet 382, 1485-1495

26. Rowe, I., Chiaravalli, M., Mannella, V., Ulisse, V., Quilici, G., Pema, M., Song, X. W., Xu, H., Mari, S., Qian, F., Pei, Y., Musco, G., and Boletta, A. (2013) Defective glucose metabolism in polycystic kidney disease identifies a new therapeutic strategy. Nat Med 19, 488-493

27. Harris, P. C., and Torres, V. E. (2014) Genetic mechanisms and signaling pathways in autosomal dominant polycystic kidney disease. The J Clin Invest 124, 2315-2324

28. LaRiviere, W. B., Irazabal, M. V., and Torres, V. E. (2015) Novel therapeutic approaches to autosomal dominant polycystic kidney disease. Transl Res 165, 488-498 
29. Ong, A. C., Devuyst, O., Knebelmann, B., Walz, G.; ERA-EDTA Working Group for Inherited Diseases (2015) Autosomal dominant polycystic kidney disease: the changing face of clinical management. Lancet 385, 1993-2002

30. Hopp, K., Hommerding, C. J., Wang, X., Ye, H., Harris, P. C., and Torres, V. E. (2015) Tolvaptan plus pasireotide shows enhanced efficacy in a PKD1 model. J Am Soc Nephrol 26, 39-47

31. Nikonova, A. S., Deneka, A. Y., Eckman, L., Kopp, M. C., Hensley, H. H., Egleston, B. L., and Golemis, E. A. (2015) Opposing Effects of Inhibitors of Aurora-A and EGFR in Autosomal-Dominant Polycystic Kidney Disease. Front Oncol 5, 228

32. Hofherr, A., Wagner, C. J., Watnick, T., and Kottgen, M. (2016) Targeted rescue of a polycystic kidney disease mutation by lysosomal inhibition. Kidney Int 89, 949-955

33. Hwang, V. J., Zhou, X., Chen, X., Trott, J., Abu Aboud, O., Shim, K., Dionne, L. K., Chmiel, K. J., Senapedis, W., Baloglu, E., Mahjoub, M. R., Li, X., and Weiss, R. H. (2017) Anticystogenic activity of a small molecule PAK4 inhibitor may be a novel treatment for autosomal dominant polycystic kidney disease. Kidney Int 92, 922-933

34. Griffiths, J., Mills, M. T., and Ong, A. C. (2020) Long-acting somatostatin analogue treatments in autosomal dominant polycystic kidney disease and polycystic liver disease: a systematic review and meta-analysis. BMJ Open 10, e032620

35. Torres, V. E., Chapman, A. B., Devuyst, O., Gansevoort, R. T., Grantham, J. J., Higashihara, E., Perrone, R. D., Krasa, H. B., Ouyang, J., Czerwiec, F. S., and Investigators, T. T. (2012) Tolvaptan in patients with autosomal dominant polycystic kidney disease. N Engl J Med 367, 2407-2418

36. Torres, V. E., Higashihara, E., Devuyst, O., Chapman, A. B., Gansevoort, R. T., Grantham, J. J., Perrone, R. D., Ouyang, J., Blais, J. D., Czerwiec, F. S.; TEMPO 3:4 Trial Investigators (2016) Effect of Tolvaptan in Autosomal Dominant Polycystic Kidney Disease by CKD Stage: Results from the TEMPO 3:4 Trial. Clin J Am Soc Nephrol 11, 803-811

37. Edwards, M. E., Chebib, F. T., Irazabal, M. V., Ofstie, T. G., Bungum, L. A., Metzger, A. J., Senum, S. R., Hogan, M. C., El-Zoghby, Z. M., Kline, T. L., Harris, P. C., Czerwiec, F. S., and Torres, V. E. (2018) Long-Term Administration of Tolvaptan in Autosomal Dominant Polycystic Kidney Disease. Clin J Am Soc Nephrol 13, 1153-1161

38. Chebib, F. T., Perrone, R. D., Chapman, A. B., Dahl, N. K., Harris, P. C., Mrug, M., Mustafa, R. A., Rastogi, A., Watnick, T., Yu, A. S. L., and Torres, V. E. (2018) A Practical Guide for Treatment of Rapidly Progressive ADPKD with Tolvaptan. J Am Soc Nephrol 29, 2458-2470

39. Blair, H. A. (2019) Tolvaptan: A Review in Autosomal Dominant Polycystic Kidney Disease. Drugs 79, 303-313

40. Nobakht, N., Hanna, R. M., Al-Baghdadi, M., Ameen, K. M., Arman, F., Nobahkt, E., Kamgar, M., and Rastogi, A. (2020) Advances in Autosomal Dominant Polycystic Kidney Disease: A Clinical Review. Kidney Med 2, 196-208

41. Chang, M. Y., and Ong A. C. M. (2018) Targeting new cellular disease pathways in autosomal dominant polycystic kidney disease. Nephrol Dial Transplant 33, 1310-1316

42. Xue, C., Dai, B., and Mei, C. (2013) Long-term treatment with mammalian target of rapamycin inhibitor does not benefit patients with autosomal dominant polycystic kidney disease: a meta-analysis. Nephron Clin Pract 124, 10-16

43. Wang, C. J., Grantham, J. J., and Wetmore, J. B. (2013) The medicinal use of water in renal disease. Kidney Int 84, 45-53

44. Torres, V. E., Bankir, L., and Grantham, J. J. (2009) A case for water in the treatment of polycystic kidney disease. Clin J Am Soc Nephrol 4, 1140-1150 
45. Wong, A. T. Y., Mannix, C., Grantham, J. J., Allman-Farinelli, M., Badve, S. V., Boudville, N., Byth, K., Chan, J., Coulshed, S., Edwards, M. E., Erickson, B. J., Fernando, M., Foster, S., Haloob, I., Harris, D. C. H., Hawley, C. M., Hill, J., Howard, K., Howell, M., Jiang, S. H., Johnson, D. W., Kline, T. L., Kumar, K., Lee, V. W., Lonergan, M., Mai, J., McCloud, P., Peduto, A., Rangan, A., Roger, S. D., Sud, K., Torres, V., Vilayur, E., and Rangan, G. K. (2018) Randomised controlled trial to determine the efficacy and safety of prescribed water intake to prevent kidney failure due to autosomal dominant polycystic kidney disease (PREVENT-ADPKD). BMJ Open 8, e018794

46. Leone, M. G., Grippa, E., Guidolin, D., Tita, B., Abdel-Haq, H., Gatto, M. T., Bordi, F., Cheng, C. Y., Silvestrini, B., and Saso, L. (2000) Effects of lonidamine on testicular and epididymal proteins in the rat. Reprod Toxicol 14, 257-263

47. Nath, K., Guo, L., Nancolas, B., Nelson, D. S., Shestov, A. A., Lee, S. C., Roman, J., Zhou, R., Leeper, D. B., Halestrap, A. P., Blair, I. A., and Glickson, J. D. (2016) Mechanism of antineoplastic activity of lonidamine. Biochim Biophys Acta 1866, 151162

48. Gong, X. D., and Wong, P. Y. (2000) Characterization of Lonidamine and AF2785 blockade of the cyclic AMP-activated chloride current in rat epididymal cells. The $J$ Membr Biol 178, 225-233

49. Gong, X. D., Wong, Y. L., Leung, G. P., Cheng, C. Y., Silvestrini, B., and Wong, P. Y. (2000) Lonidamine and analogue AF2785 block the cyclic adenosine 3', 5'monophosphate-activated chloride current and chloride secretion in the rat epididymis. Biol Reprod 63, 833-838

50. Gong, X., Burbridge, S. M., Lewis, A. C., Wong, P. Y., and Linsdell, P. (2002) Mechanism of lonidamine inhibition of the CFTR chloride channel. Br J Pharmacol 137, 928-936

51. Di Cosimo, S., Ferretti, G., Papaldo, P., Carlini, P., Fabi, A., and Cognetti, F. (2003) Lonidamine: efficacy and safety in clinical trials for the treatment of solid tumors. Drugs Today (Barc) 39, 157-174

52. Tash, J. S., Chakrasali, R., Jakkaraj, S. R., Hughes, J., Smith, S. K., Hornbaker, K., Heckert, L. L., Ozturk, S. B., Hadden, M. K., Kinzy, T. G., Blagg, B. S., and Georg, G. I. (2008) Gamendazole, an orally active indazole carboxylic acid male contraceptive agent, targets HSP90AB1 (HSP90BETA) and EEF1A1 (eEF1A), and stimulates II1a transcription in rat Sertoli cells. Biol Reprod 78, 1139-1152

53. Matts, R. L., Brandt, G. E., Lu, Y., Dixit, A., Mollapour, M., Wang, S., Donnelly, A. C., Neckers, L., Verkhivker, G., and Blagg, B. S. (2011) A systematic protocol for the characterization of Hsp90 modulators. Bioorg Med Chem 19, 684-692

54. Olesen, S. H., Ingles, D. J., Zhu, J. Y., Martin, M. P., Betzi, S., Georg, G. I., Tash, J. S., and Schonbrunn, E. (2015) Stability of the human Hsp90-p50Cdc37 chaperone complex against nucleotides and Hsp90 inhibitors, and the influence of phosphorylation by casein kinase 2. Molecules 20, 1643-1660

55. Tash, J. S., Attardi, B., Hild, S. A., Chakrasali, R., Jakkaraj, S. R., and Georg, G. I. (2008) A novel potent indazole carboxylic acid derivative blocks spermatogenesis and is contraceptive in rats after a single oral dose. Biol Reprod 78, 1127-1138

56. Taipale, M., Jarosz, D. F., and Lindquist, S. (2010) HSP90 at the hub of protein homeostasis: emerging mechanistic insights. Nat Rev Mol Cell Biol 11, 515-528

57. Li, J., and Buchner, J. (2013) Structure, function and regulation of the hsp90 machinery. Biomed J 36, 106-117

58. Whitesell, L., and Lindquist, S. L. (2005) HSP90 and the chaperoning of cancer. Nat Rev Cancer 5, 761-772 
59. Taldone, T., Gozman, A., Maharaj, R., and Chiosis, G. (2008) Targeting Hsp90: smallmolecule inhibitors and their clinical development. Curr Opin Pharmacol 8, 370-374

60. Pearl, L. H., Prodromou, C., and Workman, P. (2008) The Hsp90 molecular chaperone: an open and shut case for treatment. Biochem $J$ 410, 439-453

61. Trepel, J., Mollapour, M., Giaccone, G., and Neckers, L. (2010) Targeting the dynamic HSP90 complex in cancer. Nat Rev Cancer 10, 537-549

62. Jafari, A., Rezaei-Tavirani, M., Farhadihosseinabadi, B., Taranejoo, S., and Zali, H. (2020) HSP90 and Co-chaperones: Impact on Tumor Progression and Prospects for Molecular-Targeted Cancer Therapy. Cancer Invest 38(5), 310-328

63. Costa, T., Raghavendra, N. M., and Penido, C. (2020) Natural heat shock protein 90 inhibitors in cancer and inflammation. Eur J Med Chem 189, 112063

64. Wilson, S. J., Amsler, K., Hyink, D. P., Li, X., Lu, W., Zhou, J., Burrow, C. R., and Wilson, P. D. (2006) Inhibition of HER-2(neu/ErbB2) restores normal function and structure to polycystic kidney disease (PKD) epithelia. Biochim Biophys Acta 1762, 647655

65. Nakanishi, K., Sweeney, W., Jr., and Avner, E. D. (2001) Segment-specific c-ErbB2 expression in human autosomal recessive polycystic kidney disease. J Am Soc Nephrol 12, 379-384

66. Yang, B., Sonawane, N. D., Zhao, D., Somlo, S., and Verkman, A. S. (2008) Smallmolecule CFTR inhibitors slow cyst growth in polycystic kidney disease. J Am Soc Nephrol 19, 1300-1310

67. Magenheimer, B. S., St John, P. L., Isom, K. S., Abrahamson, D. R., De Lisle, R. C., Wallace, D. P., Maser, R. L., Grantham, J. J., and Calvet, J. P. (2006) Early embryonic renal tubules of wild-type and polycystic kidney disease kidneys respond to cAMP stimulation with cystic fibrosis transmembrane conductance regulator/ $\mathrm{Na}(+), \mathrm{K}(+), 2 \mathrm{Cl}(-)$ Co-transporter-dependent cystic dilation. J Am Soc Nephrol 17, 3424-3437

68. Natoli, T. A., Smith, L. A., Rogers, K. A., Wang, B., Komarnitsky, S., Budman, Y., Belenky, A., Bukanov, N. O., Dackowski, W. R., Husson, H., Russo, R. J., Shayman, J. A., Ledbetter, S. R., Leonard, J. P., and Ibraghimov-Beskrovnaya, O. (2010) Inhibition of glucosylceramide accumulation results in effective blockade of polycystic kidney disease in mouse models. Nat Med 16, 788-792

69. Boletta, A. (2009) Emerging evidence of a link between the polycystins and the mTOR pathways. Pathogenetics 2, 6

70. Bukanov, N. O., Smith, L. A., Klinger, K. W., Ledbetter, S. R., and IbraghimovBeskrovnaya, O. (2006) Long-lasting arrest of murine polycystic kidney disease with CDK inhibitor roscovitine. Nature 444, 949-952

71. Yamaguchi, T., Reif, G. A., Calvet, J. P., and Wallace, D. P. (2010) Sorafenib inhibits cAMP-dependent ERK activation, cell proliferation, and in vitro cyst growth of human ADPKD cyst epithelial cells. Am J Physiol Renal Physiol 299, F944-951

72. Park, E. Y., Sung, Y. H., Yang, M. H., Noh, J. Y., Park, S. Y., Lee, T. Y., Yook, Y. J., Yoo, K. H., Roh, K. J., Kim, I., Hwang, Y. H., Oh, G. T., Seong, J. K., Ahn, C., Lee, H. W., and Park, J. H. (2009) Cyst formation in kidney via B-Raf signaling in the PKD2 transgenic mice. J Biol Chem 284, 7214-7222

73. Shibazaki, S., Yu, Z., Nishio, S., Tian, X., Thomson, R. B., Mitobe, M., Louvi, A., Velazquez, H., Ishibe, S., Cantley, L. G., Igarashi, P., and Somlo, S. (2008) Cyst formation and activation of the extracellular regulated kinase pathway after kidney specific inactivation of Pkd1. Hum Mol Genet 17, 1505-1516

74. Parker, E., Newby, L. J., Sharpe, C. C., Rossetti, S., Streets, A. J., Harris, P. C., O'Hare, M. J., and Ong, A. C. (2007) Hyperproliferation of PKD1 cystic cells is induced 
by insulin-like growth factor-1 activation of the Ras/Raf signalling system. Kidney Int 72, 157-165

75. Smithline, Z. B., Nikonova, A. S., Hensley, H. H., Cai, K. Q., Egleston, B. L., Proia, D. A., Seeger-Nukpezah, T., and Golemis, E. A. (2014) Inhibiting heat shock protein 90 (HSP90) limits the formation of liver cysts induced by conditional deletion of Pkd1 in mice. PLoS One 9, e114403

76. $\quad$ Seeger-Nukpezah, T., Proia, D. A., Egleston, B. L., Nikonova, A. S., Kent, T., Cai, K. Q., Hensley, H. H., Ying, W., Chimmanamada, D., Serebriiskii, I. G., and Golemis, E. A. (2013) Inhibiting the HSP90 chaperone slows cyst growth in a mouse model of autosomal dominant polycystic kidney disease. Proc Natl Acad Sci USA 110, 1278612791

77. Nikonova, A. S., Deneka, A. Y., Kiseleva, A. A., Korobeynikov, V., Gaponova, A., Serebriiskii, I. G., Kopp, M. C., Hensley, H. H., Seeger-Nukpezah, T. N., Somlo, S., Proia, D. A., and Golemis, E. A. (2018) Ganetespib limits ciliation and cystogenesis in autosomal-dominant polycystic kidney disease (ADPKD). FASEB J 32, 2735-2746

78. Wallace, D. P., Grantham, J. J., and Sullivan, L. P. (1996) Chloride and fluid secretion by cultured human polycystic kidney cells. Kidney Int 50, 1327-1336

79. Wallace, D. P., and Reif, G. A. (2019) Generation of primary cells from ADPKD and normal human kidneys. Methods Cell Biol 153, 1-23

80. Stoos, B. A., Naray-Fejes-Toth, A., Carretero, O. A., Ito, S., and Fejes-Toth, G. (1991) Characterization of a mouse cortical collecting duct cell line. Kidney Int 39, 1168-1175

81. Herron, B. J., Lu, W., Rao, C., Liu, S., Peters, H., Bronson, R. T., Justice, M. J., McDonald, J. D., and Beier, D. R. (2002) Efficient generation and mapping of recessive developmental mutations using ENU mutagenesis. Nat Genet 30, 185-189

82. Avner, E. D., Ellis, D., Temple, T., and Jaffe, R. (1982) Metanephric development in serum-free organ culture. In Vitro 18, 675-682

83. Welham, S. J., and Woolf, A. S. (2003) Organ culture of intact metanephric kidneys. Methods Mol Med 86, 169-177

84. Maser, R. L., Magenheimer, B. S., and Calvet, J. P. (2019) Metanephric Organ Culture. Methods Cell Biol 153, 169-183

85. Akner, G., Mossberg, K., Sundqvist, K. G., Gustafsson, J. A., and Wikstrom, A. C. (1992) Evidence for reversible, non-microtubule and non-microfilament-dependent nuclear translocation of hsp90 after heat shock in human fibroblasts. Eur J Cell Biol 58, 356-364

86. Sidera, K., and Patsavoudi, E. (2014) HSP90 inhibitors: current development and potential in cancer therapy. Recent Pat Anticancer Drug Discov 9, 1-20

87. Matei, D., Satpathy, M., Cao, L., Lai, Y. C., Nakshatri, H., and Donner, D. B. (2007) The platelet-derived growth factor receptor alpha is destabilized by geldanamycins in cancer cells. J Biol Chem 282, 445-453

88. Loo, M. A., Jensen, T. J., Cui, L., Hou, Y., Chang, X. B., and Riordan, J. R. (1998) Perturbation of Hsp90 interaction with nascent CFTR prevents its maturation and accelerates its degradation by the proteasome. EMBO J 17, 6879-6887

89. Joly, D., Morel, V., Hummel, A., Ruello, A., Nusbaum, P., Patey, N., Noel, L. H., Rousselle, P., and Knebelmann, B. (2003) Beta4 integrin and laminin 5 are aberrantly expressed in polycystic kidney disease: role in increased cell adhesion and migration. Am J Pathol 163, 1791-1800

90. Murray, J. W., Edmonds, B. T., Liu, G., and Condeelis, J. (1996) Bundling of actin filaments by elongation factor 1 alpha inhibits polymerization at filament ends. $J$ Cell Biol 135, 1309-1321 
91. Gross, S. R., and Kinzy, T. G. (2005) Translation elongation factor 1A is essential for regulation of the actin cytoskeleton and cell morphology. Nat Struct Mol Biol 12, 772778

92. Kamal, A., Thao, L., Sensintaffar, J., Zhang, L., Boehm, M. F., Fritz, L. C., and Burrows, F. J. (2003) A high-affinity conformation of Hsp90 confers tumour selectivity on Hsp90 inhibitors. Nature 425, 407-410

93. Graner, M. W. (2016) HSP90 and Immune Modulation in Cancer. Adv Cancer Res 129, 191-224

94. Solarova, Z., Mojzis, J., and Solar, P. (2015) Hsp90 inhibitor as a sensitizer of cancer cells to different therapies (review). Int J Oncol 46, 907-926

95. Seeger-Nukpezah, T., Geynisman, D. M., Nikonova, A. S., Benzing, T., and Golemis, E. A. (2015) The hallmarks of cancer: relevance to the pathogenesis of polycystic kidney disease. Nat Rev Nephrol 11(9), 515-534

96. Grantham, J. J. (1990) Polycystic kidney disease: neoplasia in disguise. Am J Kidney Dis 15, 110-116

97. Hanaoka, K., Devuyst, O., Schwiebert, E. M., Wilson, P. D., and Guggino, W. B. (1996) A role for CFTR in human autosomal dominant polycystic kidney disease. Am J Physiol 270, C389-399

98. Davidow, C. J., Maser, R. L., Rome, L. A., Calvet, J. P., and Grantham, J. J. (1996) The cystic fibrosis transmembrane conductance regulator mediates transepithelial fluid secretion by human autosomal dominant polycystic kidney disease epithelium in vitro. Kidney Int 50, 208-218

99. Cowley, B. D., Jr., Smardo, F. L., Jr., Grantham, J. J., and Calvet, J. P. (1987) Elevated C-myc protooncogene expression in autosomal recessive polycystic kidney disease. Proc Natl Acad Sci USA 84, 8394-8398

100. MacKay, K., Striker, L. J., Pinkert, C. A., Brinster, R. L., and Striker, G. E. (1987) Glomerulosclerosis and renal cysts in mice transgenic for the early region of SV40. Kidney Int 32, 827-837

101. Trudel, M., D'Agati, V., and Costantini, F. (1991) C-myc as an inducer of polycystic kidney disease in transgenic mice. Kidney Int 39, 665-671

102. Schaffner, D. L., Barrios, R., Massey, C., Banez, E. I., Ou, C. N., Rajagopalan, S., Aguilar-Cordova, E., Lebovitz, R. M., Overbeek, P. A., and Lieberman, M. W. (1993) Targeting of the rasT24 oncogene to the proximal convoluted tubules in transgenic mice results in hyperplasia and polycystic kidneys. Am J Pathol 142, 1051-1060

103. Fukuyo, Y., Hunt, C. R., and Horikoshi, N. (2010) Geldanamycin and its anti-cancer activities. Cancer Lett 290, 24-35

104. Montagut, C., and Settleman, J. (2009) Targeting the RAF-MEK-ERK pathway in cancer therapy. Cancer Lett 283, 125-134

105. Whittaker, S., Marais, R., and Zhu, A. X. (2010) The role of signaling pathways in the development and treatment of hepatocellular carcinoma. Oncogene 29, 4989-5005

106. Qian, C. N., Knol, J., Igarashi, P., Lin, F., Zylstra, U., Teh, B. T., and Williams, B. O. (2005) Cystic renal neoplasia following conditional inactivation of apc in mouse renal tubular epithelium. J Biol Chem 280, 3938-3945

107. Ikeda, M., Fong, P., Cheng, J., Boletta, A., Qian, F., Zhang, X. M., Cai, H., Germino, G. G., and Guggino, W. B. (2006) A regulatory role of polycystin-1 on cystic fibrosis transmembrane conductance regulator plasma membrane expression. Cell Physiol Biochem 18, 9-20 
108. Ditonno, P., Battaglia, M., Selvaggio, O., Garofalo, L., Lorusso, V., and Selvaggi, F. P. (2005) Clinical Evidence Supporting the Role of Lonidamine for the Treatment of BPH. Rev Urol 7 Suppl 7, S27-33

109. Brawer, M. K. (2005) Lonidamine: basic science and rationale for treatment of prostatic proliferative disorders. Rev Urol 7 Suppl 7, S21-26

110. Fanciulli, M., Valentini, A., Bruno, T., Citro, G., Zupi, G., and Floridi, A. (1996) Effect of the antitumor drug lonidamine on glucose metabolism of adriamycin-sensitive and resistant human breast cancer cells. Oncol Res 8, 111-120

111. Paggi, M. G., Fanciulli, M., Perrotti, N., Floridi, A., Zeuli, M., Silvestrini, B., and Caputo, A. (1988) The role of mitochondrial hexokinase in neoplastic phenotype and its sensitivity to lonidamine. Ann N Y Acad Sci 551, 358-360

112. Silvestrini, B., and Caputo, A. (1981) Lonidamine: a new pharmacological approach to the study and control of spermatogenesis and tumors. Chemotherapy 27 Suppl 2, 1-120

113. Shillingford, J. M., Murcia, N. S., Larson, C. H., Low, S. H., Hedgepeth, R., Brown, N., Flask, C. A., Novick, A. C., Goldfarb, D. A., Kramer-Zucker, A., Walz, G., Piontek, K. B., Germino, G. G., and Weimbs, T. (2006) The mTOR pathway is regulated by polycystin1 , and its inhibition reverses renal cystogenesis in polycystic kidney disease. Proc Natl Acad Sci USA 103, 5466-5471

114. Sullivan, L. P., Wallace, D. P., and Grantham, J. J. (1998) Chloride and fluid secretion in polycystic kidney disease. J Am Soc Nephrol 9, 903-916

115. Del Bufalo, D., Trisciuoglio, D., Scarsella, M., D'Amati, G., Candiloro, A., lervolino, A., Leonetti, C., and Zupi, G. (2004) Lonidamine causes inhibition of angiogenesis-related endothelial cell functions. Neoplasia 6, 513-522

116. Malorni, W., Meschini, S., Matarrese, P., and Arancia, G. (1992) The cytoskeleton as a subcellular target of the antineoplastic drug lonidamine. Anticancer Res 12, 2037-2045

117. Demma, M., Warren, V., Hock, R., Dharmawardhane, S., and Condeelis, J. (1990) Isolation of an abundant 50,000-dalton actin filament bundling protein from Dictyostelium amoebae. J Biol Chem 265, 2286-2291

118. Whitesell, L., Bagatell, R., and Falsey, R. (2003) The stress response: implications for the clinical development of hsp90 inhibitors. Curr Cancer Drug Targets 3, 349-358

119. Guo, F., Rocha, K., Bali, P., Pranpat, M., Fiskus, W., Boyapalle, S., Kumaraswamy, S., Balasis, M., Greedy, B., Armitage, E. S., Lawrence, N., and Bhalla, K. (2005) Abrogation of heat shock protein 70 induction as a strategy to increase antileukemia activity of heat shock protein 90 inhibitor 17-allylamino-demethoxy geldanamycin. Cancer Res 65, 10536-10544

120. Schmitt, E., Gehrmann, M., Brunet, M., Multhoff, G., and Garrido, C. (2007) Intracellular and extracellular functions of heat shock proteins: repercussions in cancer therapy. $J$ Leukoc Biol 81, 15-27 

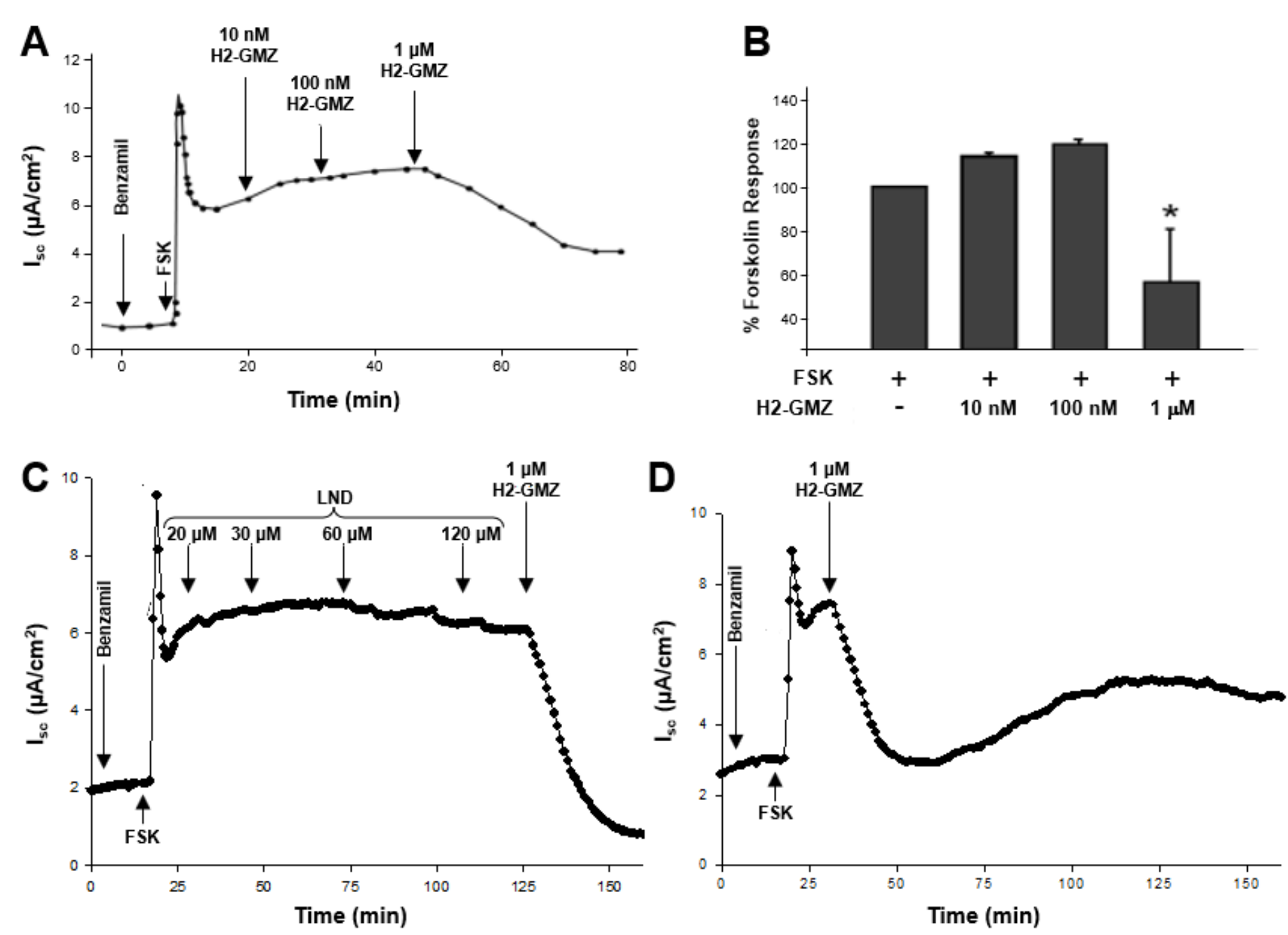

Fig. 1. H2-GMZ inhibits CFTR-mediated short-circuit current in ADPKD monolayers. A and B, Apical treatment with H2-GMZ inhibits forskolin-induced short-circuit current in ADPKD monolayers. Confluent monolayers of human ADPKD cells treated apically with benzamil, then forskolin to first block the ENaC channel and then induce CFTR-current. Increasing concentrations of $\mathrm{H} 2-\mathrm{GMZ}$ were added and the change in current recorded. The graph represents the average of four different monolayers from two ADPKD kidneys. *, the effect was statistically significant at $p<0.05$ as determined by

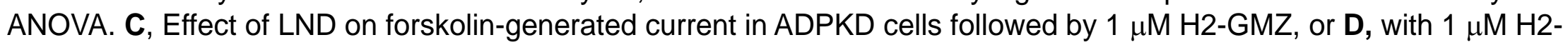
GMZ alone. 
A H2-GMZ + cAMP or EGF
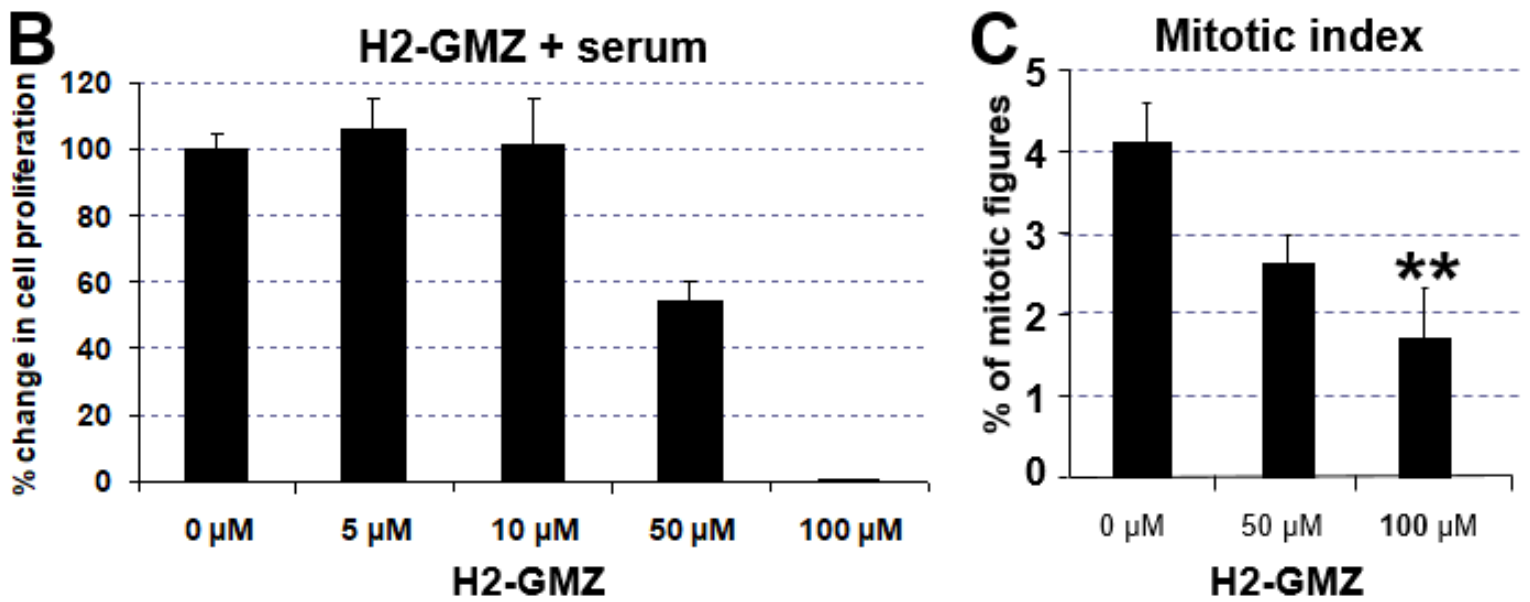

$\begin{array}{rrrrrrr}D \text { Hours } & 24 & 48 & 72 & 24 & 48 & 72 \\ \text { H2-GMZ } & - & - & - & + & + & +\end{array}$

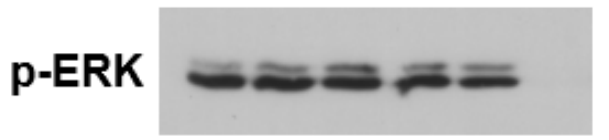

ERK

$\mathbf{R b} \rightrightarrows$

Fig. 2. Dose-dependent decrease in the proliferation of primary human ADPKD cells treated with H2-GMZ. A and B, Dose response of ADPKD cells stimulated with $100 \mu \mathrm{M}$ cAMP, $25 \mathrm{ng} / \mathrm{ml}$ EGF or $5 \%$ FBS and treated with H2-GMZ. After 72 hours of treatment, MTT assays were performed. In each group, results were expressed as a percentage of the control group (not treated with $\mathrm{H} 2-\mathrm{GMZ}$ ). The error bars indicate a standard error for $\mathrm{n}=6$. C, ADPKD cells stimulated with $5 \% \mathrm{FBS}$ and treated with $\mathrm{H} 2-\mathrm{GMZ}$ show a significant decrease in the number of mitotic figures. Cells were stained with DAPI to visualize the nuclei. Statistical analysis was done using One-way ANOVA and the Tukey HSD test for pair-wise comparisons. ${ }^{* *}$ indicates $p<0.01 . \mathbf{D}$, Inhibition of $p$-ERK and hyperphosphorylated $\mathrm{Rb}$ in $\mathrm{H} 2-\mathrm{GMZ}$ treated ADPKD cells correlates with the inhibition of cell proliferation. In growing cells, there is a doublet of hyper- (upper) and hypo- or non-phosphorylated (lower) Rb (retinoblastoma) protein. H2-GMZ treatment decreased the levels of hyperphosphorylated $\mathrm{Rb}$ (upper arrow) consistent with decreased cell proliferation. Cytoplasmic extracts were prepared following 24,48 or 72 hours of $50 \mu \mathrm{M} \mathrm{H} 2-\mathrm{GMZ}$ treatment in the presence of serum and analyzed by Western blotting. 

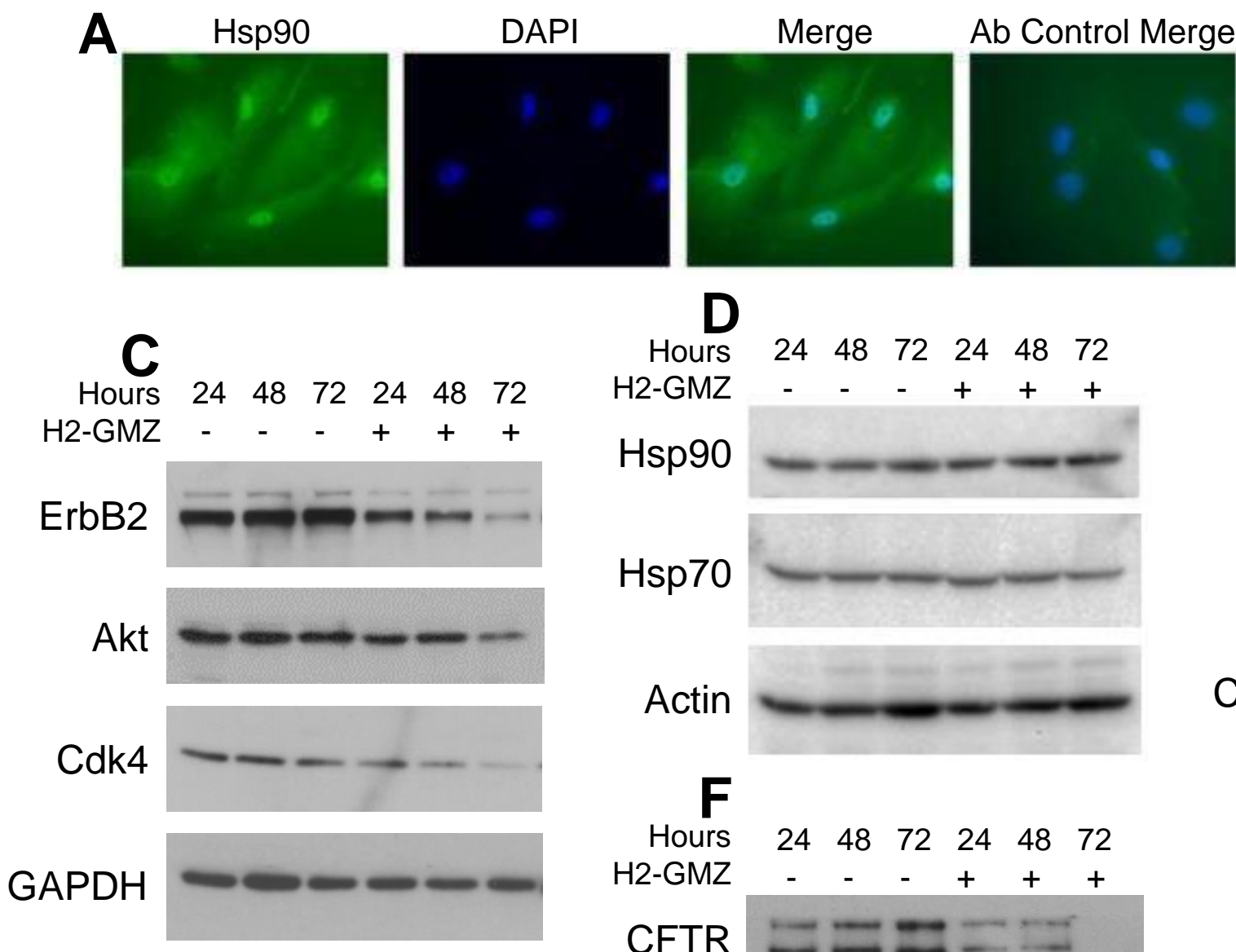

D

\begin{abstract}
Hours
\end{abstract}
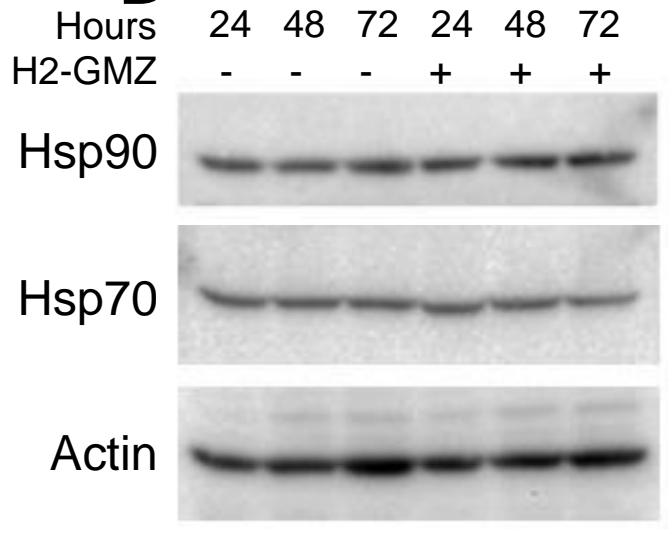

$\mathbf{F}$

Hours

H2-GMZ

CFTR
B

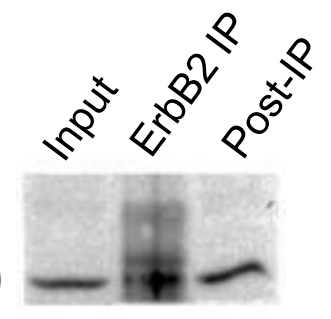

ErbB2

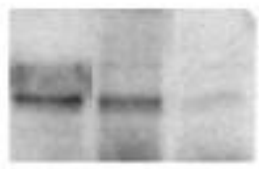

E

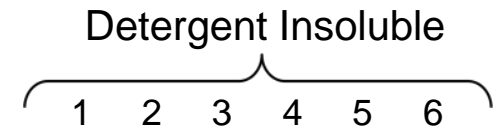

Akt

Cdk4

1: Control (DMSO)

2: 100 nM MG132

3: $50 \mu \mathrm{M} \mathrm{H} 2-\mathrm{GMZ}$

4: MG132 + H2-GMZ

5: $10 \mu \mathrm{M}$ 17-AAG

6: MG132 + 17-AAG

Fig. 3. H2-GMZ blocks Hsp90 function in primary human ADPKD cells. A, ADPKD cells were stained with anti-Hsp90 antibody (green) to show the presence of Hsp90 in the cytoplasm and nucleus. Cells were counterstained with the nuclear stain DAPI (blue). The control well was incubated with FITCconjugated secondary antibody alone. B, Hsp90 and client protein ErbB2 remain associated in ADPKD cells. ErbB2 was immunoprecipitated from ADPKD cell lysate and the association with Hsp90 was determined by Western blotting. C and D, H2-GMZ treatment decreases Hsp90 client protein levels. ADPKD cells were treated for 24, 48 or 27 hours with $50 \mu \mathrm{M} \mathrm{H} 2-\mathrm{GMZ}$ and analyzed by Western blotting. GAPDH and Actin served as internal controls. E, H2-GMZ targets Hsp90 client proteins for degradation via the proteasome pathway. ADPKD cells treated with H2-GMZ for 24 hours in the presence or absence of MG132, a proteasome inhibitor, were lysed in buffer containing Triton-X 100 and the insoluble material was pelleted and analyzed by Western blotting. 17-AAG was used as a positive control for the inhibition of the proteasomal pathway. F, H2-GMZ treatment decreases CFTR protein levels. All results are representative of three independent experiments with cells from three different ADPKD kidneys. 


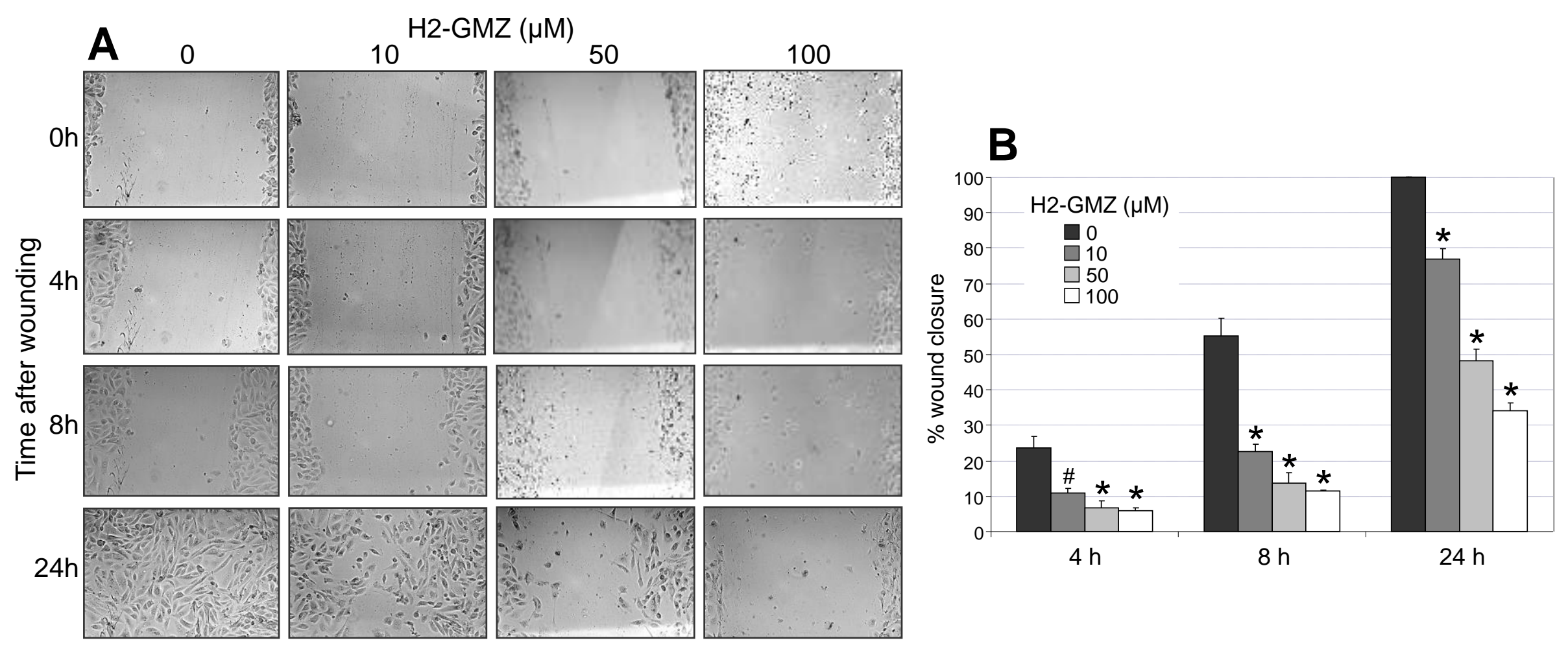

Fig. 4. H2-GMZ treatment inhibits cell migration. A, Confluent monolayers of human ADPKD cells were scratched with a P20 pipette tip, then treated with increasing concentrations of H2-GMZ. Wound images were captured at 10x magnification immediately after wounding and at 4, 8 and 24 hours post-wounding. B, Percentage of wound closure was calculated by subtracting the area of the wound at any given time point from the $0 \mathrm{~h}$ wound area expressed as a percentage of the $0 \mathrm{~h}$ wound area. Statistical analysis was done to compare the H2-GMZ-treated cells to untreated cells at each time point using One-way ANOVA and the Tukey HSD test for pair-wise comparisons. \# : $p<0.05,{ }^{*}: p<0.01$. The assay was done in triplicate. 

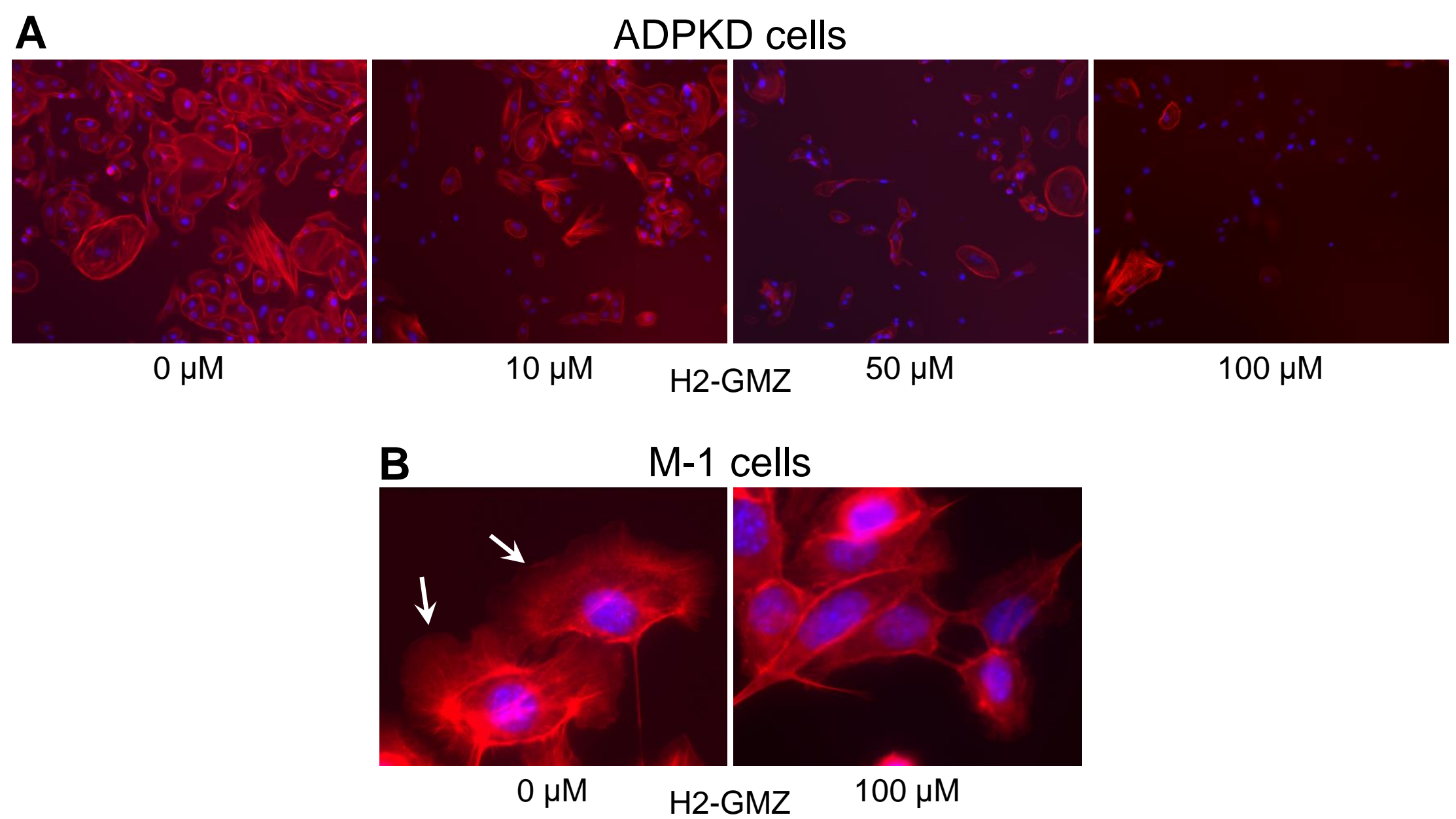

Fig. 5. H2-GMZ treatment affects the actin cytoskeleton. A and B, Human ADPKD cells or mouse M-1 cortical collecting duct cells were treated with increasing concentrations of $\mathrm{H} 2-\mathrm{GMZ}$ and stained with phalloidin. Images were captured at $10 \mathrm{x}$ (A) or 60x (B) using the same exposure settings for treated and untreated cells. Red color shows phalloidin bound to actin filaments in the cell. Blue indicates DAPI-stained nuclei. The assay was done in triplicate. 
Fig. 6

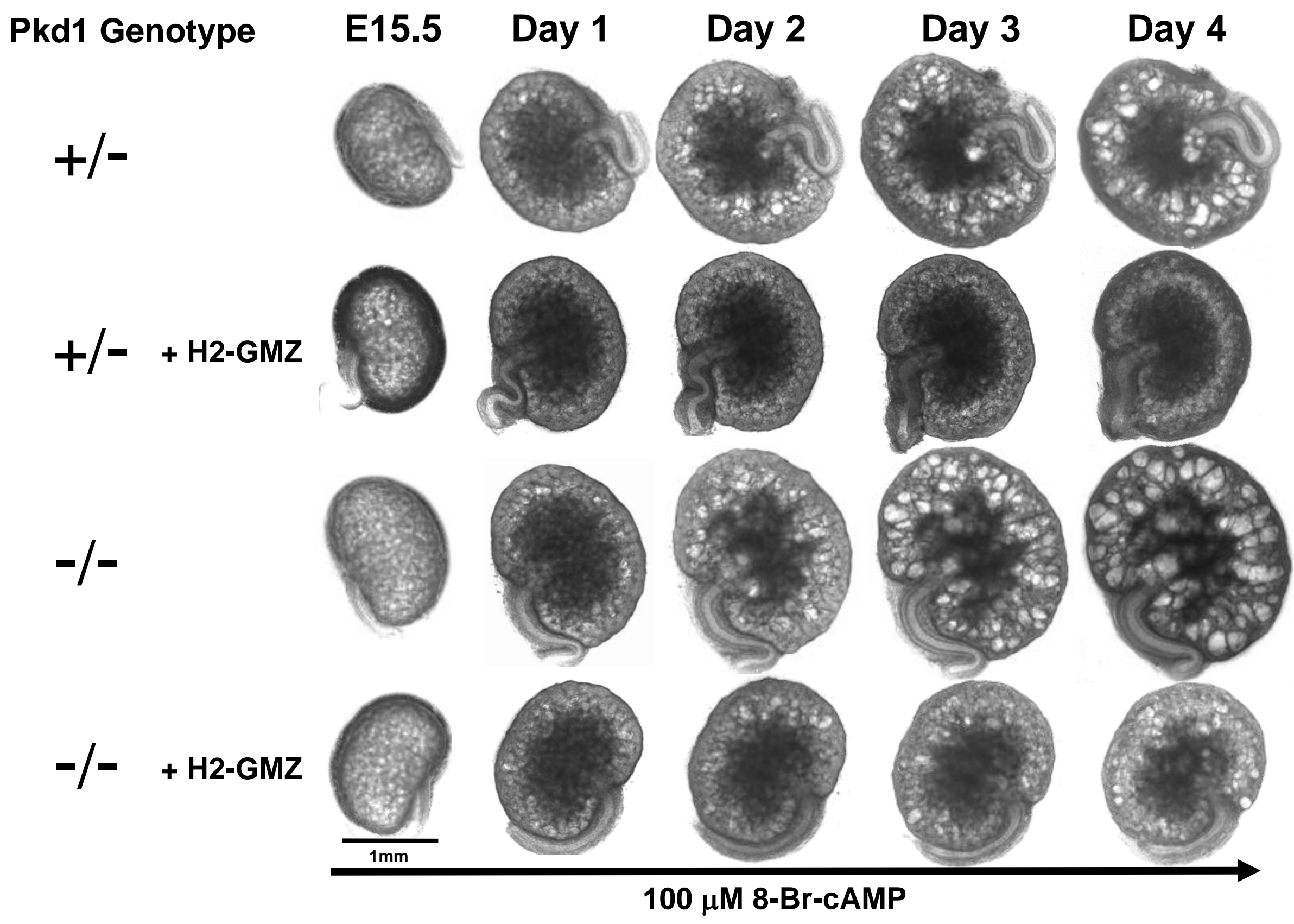




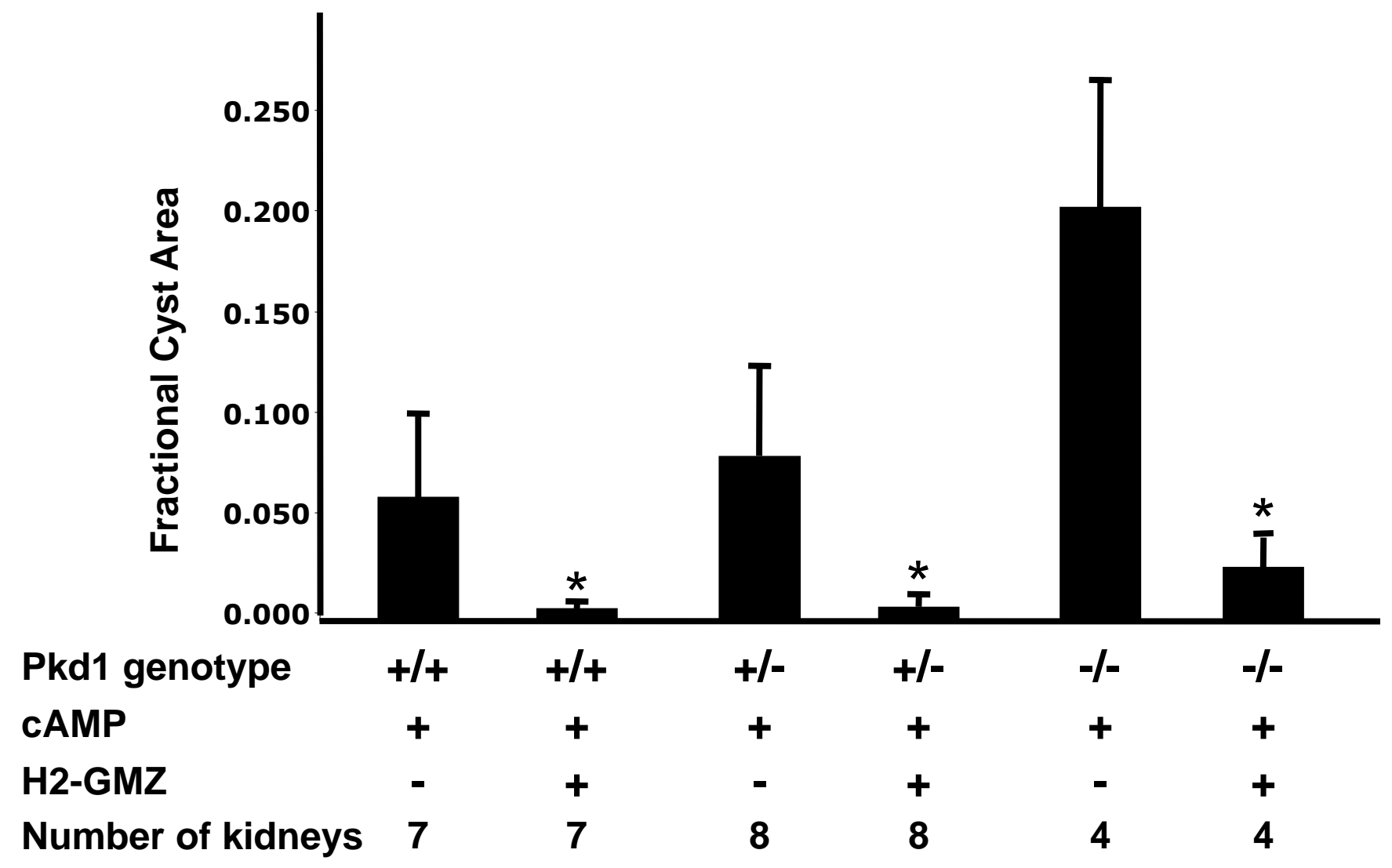

Fig. 6. H2-GMZ treatment reduces the cyst burden in CAMP-treated metanephric kidneys. Embryonic day 15.5 mouse kidneys from Pkd1 +/- and -/- mice were plated on Transwell membranes and treated with $100 \mu \mathrm{M}$ cAMP with or without $5 \mu \mathrm{M}$ H2GMZ for four days. H2-GMZ treatment reduced the cystic index of treated kidneys. Fractional cyst area is the total area of all the cysts per kidney represented as a fraction of the total area of the kidney. The number of kidneys of each genotype is listed. ${ }^{*}$, the effect was statistically significant at $p<0.01$ as determined by Student's t-test. 
A

\section{$\mathrm{H}_{2} \mathrm{O}$}

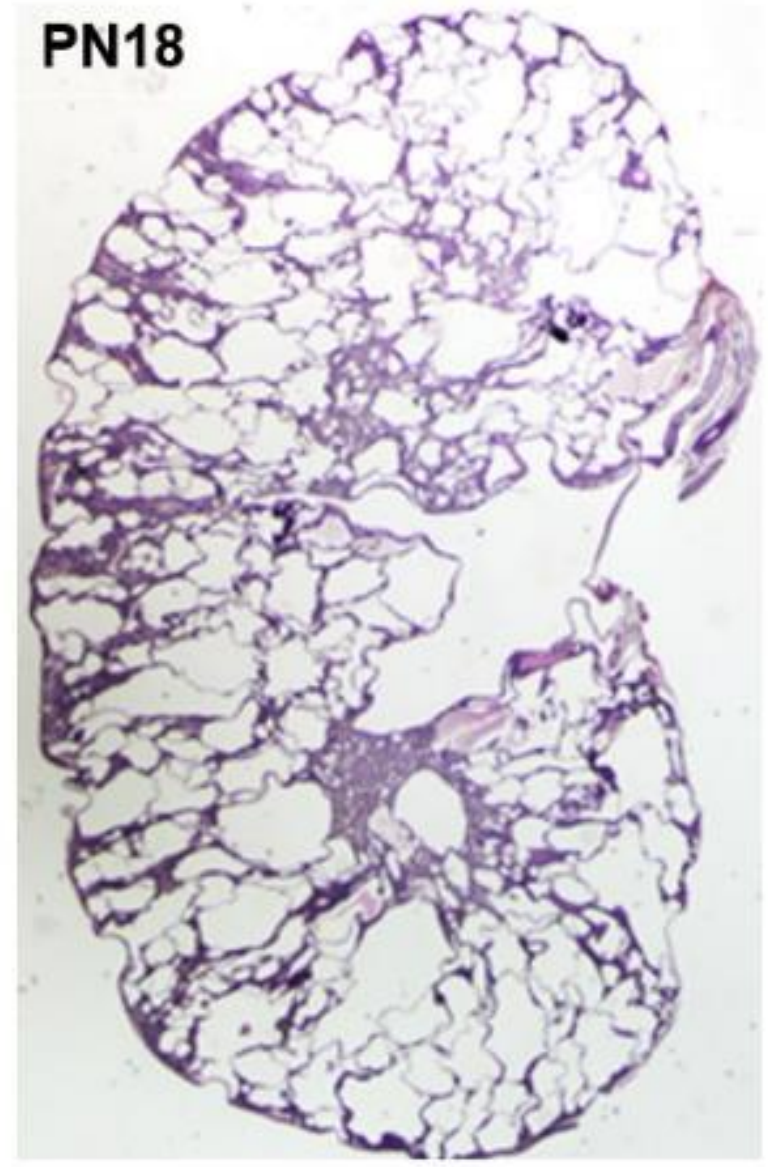

H2-GMZ

\section{PN18}

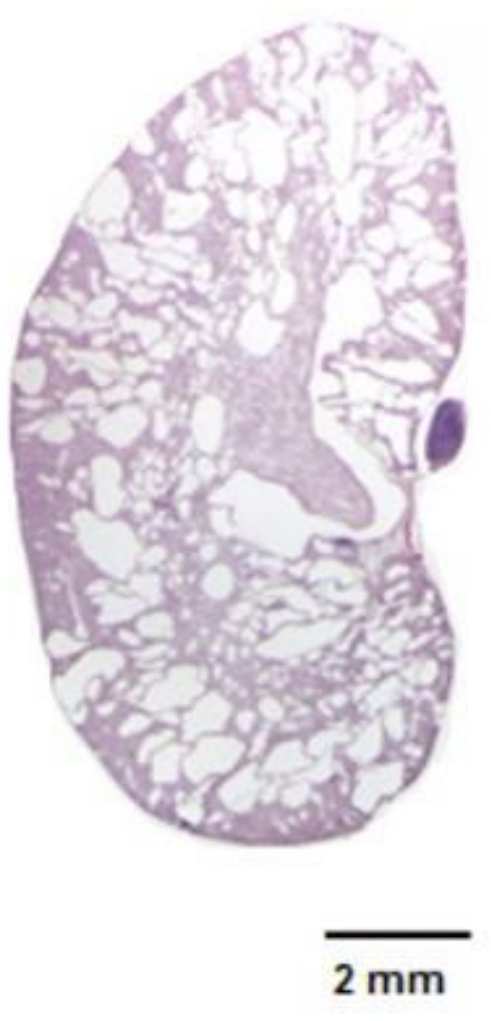

Fig. 7. H2-GMZ treatment decreases cystic burden in vivo in a Pkd1 mouse model. H2-GMZ treatment was carried out on Pkd1 1lox/flox:Pkhd1-Cre mice using daily i.p. injections of $20 \mathrm{mg} / \mathrm{kg} \mathrm{H} 2-\mathrm{GMZ}$ from postnatal day 8 to 18 . A and B, Mice treated with H2-GMZ had a significantly reduced cystic index, smaller kidneys and increased renal parenchyma, decreased kidney weight to body weight (KW/BW) and improved blood urea nitrogen (BUN) levels. C, Survival studies showed significantly longer survival for H2-GMZ-treated mice (Control vs H2-GMZ: $28.8 \pm 5$ vs $67.8 \pm 23 ; p<0.01$ ). 

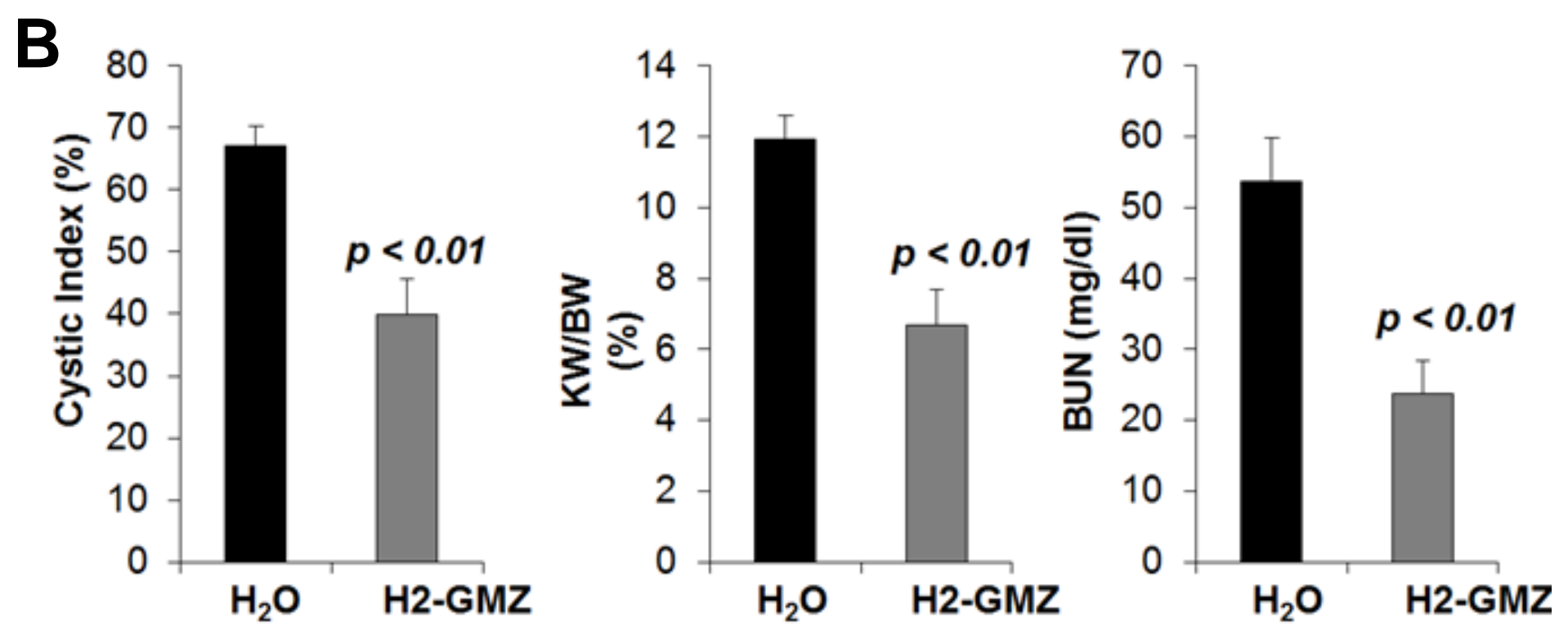

Fig. 7. H2-GMZ treatment decreases cystic burden in vivo in a Pkd1 mouse model. H2-GMZ treatment was carried out on Pkd1 1lox/flox:Pkhd1-Cre mice using daily i.p. injections of $20 \mathrm{mg} / \mathrm{kg} \mathrm{H} 2-\mathrm{GMZ}$ from postnatal day 8 to 18 . A and $\mathbf{B}$, Mice treated with H2-GMZ had a significantly reduced cystic index, smaller kidneys and increased renal parenchyma, decreased kidney weight to body weight (KW/BW) and improved blood urea nitrogen (BUN) levels. C, Survival studies showed significantly longer survival for H2-GMZ-treated mice (Control vs H2-GMZ: $28.8 \pm 5$ vs $67.8 \pm 23 ; p<0.01$ ). 


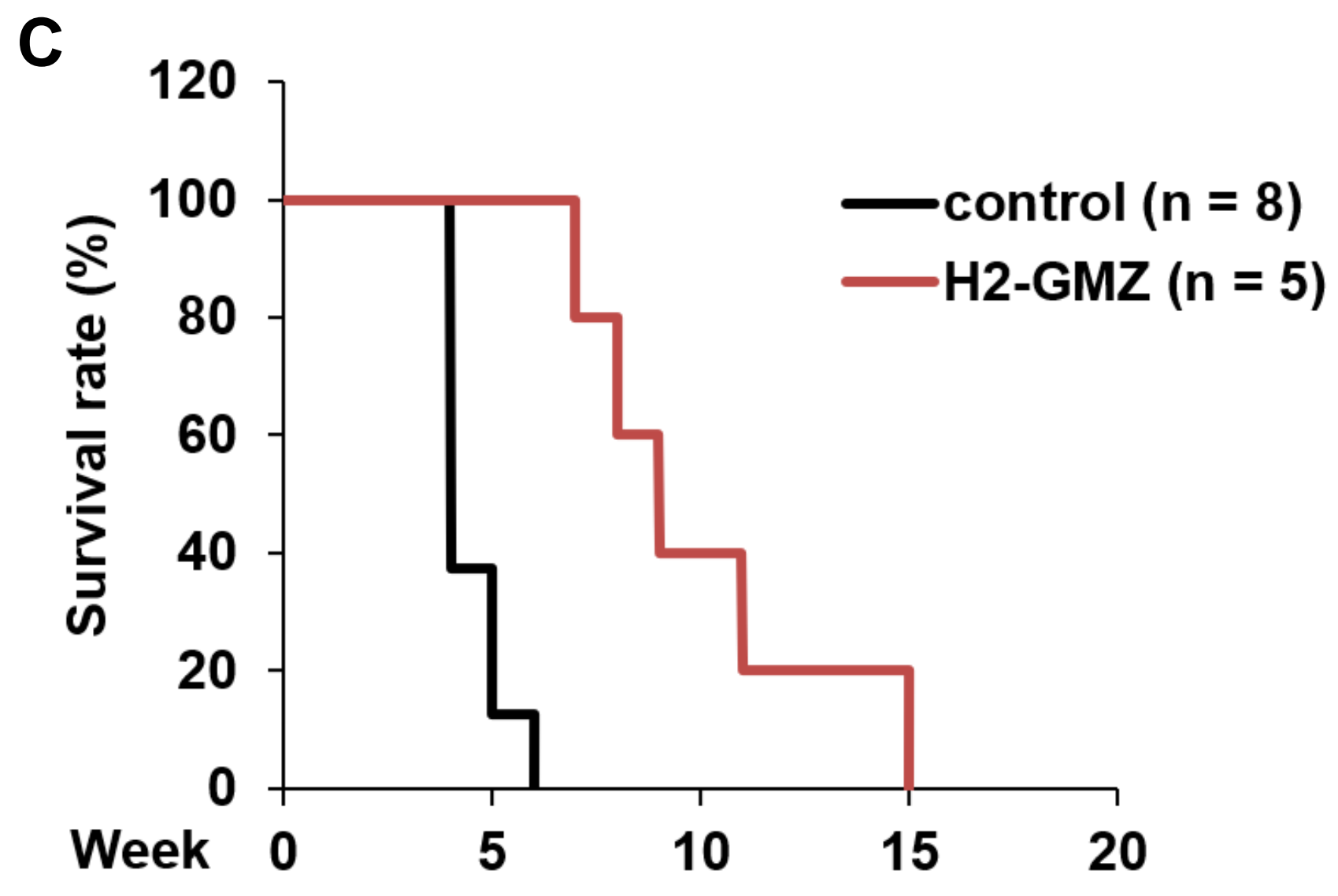

Fig. 7. H2-GMZ treatment decreases cystic burden in vivo in a Pkd1 mouse model. H2-GMZ treatment was carried out on Pkd1 flox/flox:Pkhd1-Cre mice using daily i.p. injections of $20 \mathrm{mg} / \mathrm{kg} \mathrm{H} 2-\mathrm{GMZ}$ from postnatal day 8 to 18 . A and B, Mice treated with $\mathrm{H} 2-\mathrm{GMZ}$ had a significantly reduced cystic index, smaller kidneys and increased renal parenchyma, decreased kidney weight to body weight (KW/BW) and improved blood urea nitrogen (BUN) levels. C, Survival studies showed significantly longer survival for H2-GMZ-treated mice (Control vs H2-GMZ: $28.8 \pm 5$ vs $67.8 \pm 23 ; p<0.01$ ). 